\title{
4-Acetylantroquinonol $B$ enhances cell death and inhibits autophagy by downregulating the PI3K/Akt/MDR1 pathway in gemcitabine-resistant pancreatic cancer cells
}

\author{
YING-YIN CHEN $^{1 *}$, SHENG-YI CHEN ${ }^{1 *}$, TSUNG-JU LI ${ }^{2}$, TING-WEI LIN ${ }^{2}$, \\ CHIN-CHU $\mathrm{CHEN}^{2}$ and GOW-CHIN YEN $^{1}$ \\ ${ }^{1}$ Department of Food Science and Biotechnology, National Chung Hsing University, Taichung 40227; \\ ${ }^{2}$ Biotech Research Institute, Grape King Bio Ltd., Taoyuan 32542, Taiwan, R.O.C.
}

Received November 19, 2021; Accepted January 25, 2022

DOI: $10.3892 / \mathrm{ol} .2022 .13248$

\begin{abstract}
Gemcitabine (GEM) is a typical chemotherapeutic drug used to treat pancreatic cancer, but GEM resistance develops within weeks after chemotherapy. Hence, the development of a new strategy to overcome drug resistance is urgent. 4-Acetylantroquinonol B (4-AAQB), a ubiquinone derived from Taiwanofungus camphoratus, has hepatoprotective, anti-obesity, and antitumor activities. However, the role of 4-AAQB in enhancing GEM sensitivity is unclear. This study aimed to determine the underlying mechanisms by which 4-AAQB enhances cytotoxicity and GEM sensitivity. Cell viability was dramatically reduced by 4 -AAQB $(2$ and $5 \mu \mathrm{M})$ treatment in the MiaPaCa-2 and GEM-resistant MiaPaCa-2 (MiaPaCa-2 ${ }^{\mathrm{GEMR}}$ ) human pancreatic cancer cells. 4-AAQB led to cell cycle arrest, upregulated the levels of reactive oxygen species (ROS), promoted apoptosis, and inhibited autophagy, which subsequently enhanced GEM chemosensitivity by suppressing the receptor for advanced glycation end products (RAGE)/high mobility group box 1 (HMGB1)-initiated $\mathrm{PI} 3 \mathrm{~K} / \mathrm{Akt} / \mathrm{multidrug}$ resistance protein 1 (MDR1) signaling pathway in both cell lines. Vascular endothelial growth factor A (VEGFA) expression, cell migration, and invasion were also inhibited by the 4-AAQB incubation. Overall,
\end{abstract}

Correspondence to: Dr Gow-Chin Yen, Department of Food Science and Biotechnology, National Chung Hsing University, 145 Xingda Road, Taichung 40227, Taiwan, R.O.C.

E-mail: gcyen@nchu.edu.tw

${ }^{*}$ Contributed equally

Abbreviations: 4-AAQB, 4-acetylantroquinonol B; ATG5, autophagy-related protein 5; HMGB1, high mobility group box 1 protein; MDR1, multidrug resistance protein 1; RAGE, receptor for advanced glycation end-products; VEGFA, vascular endothelial growth factor $\mathrm{A}$

Key words: 4-acetylantroquinonol B, apoptosis, autophagy, gemcitabine, pancreatic cancer, cell invasion this combination treatment strategy might represent a novel approach for GEM-resistant pancreatic cancer.

\section{Introduction}

According to cancer statistics from the American Cancer Society, pancreatic cancer is characterized by the lowest 5-year survival rate (10\%) among all cancers (1). In addition, early diagnosis is extremely difficult due to the nonspecific symptoms of pancreatic cancer (2). Notably, $80-85 \%$ of patients with local invasion and distant metastasis at the diagnosis of pancreatic cancer receive systemic therapy with gemcitabine (3). Gemcitabine (GEM), a deoxycytidine nucleotide analog, is a typical first-line chemotherapeutic drug for pancreatic cancer treatment. Unfortunately, GEM resistance frequently occurs in patients with pancreatic cancer, which results in a high incidence, high mortality, and substantial disease burden in patients $(4,5)$. In addition, a 5-year survival rate below $5 \%$ is found in patients with drug-resistant and metastatic pancreatic cancer, suggesting that drug resistance is a critical problem that urgently needs to be solved (6). The available evidence described above indicates that a late diagnosis and high therapeutic resistance are the major challenges in pancreatic cancer treatment. Thus, the development of a new strategy designed to enhance GEM chemosensitivity may be beneficial for pancreatic cancer treatment.

Taiwanofungus camphoratus (Antrodia cinnamomea), often referred to as 'Niu-chang-chih', is a medicinal fungus that only grows on the native tree Cinnamomum kanehirai Hayata in Taiwan (7). Several bioactive compounds are present in Taiwanofungus camphoratus, including polysaccharides, triterpenes, diterpenes, succinic acid derivatives, and ubiquinone (7). 4-Acetylantroquinonol B (4-AAQB) is the ubiquinone derivative of Taiwanofungus camphoratus, which is identified as the major antiproliferative compound for hepatoma cells (8). In addition, 4-AAQB is known to participate in modulating many physiological and pathological processes, such as anti-inflammatory and antioxidant ability (9), amelioration of nonalcoholic steatohepatitis (9) and inhibition of osteoclast formation (10), breast cancer (11), glioblastoma (12), and hepatic cancer stem cell tumorigenicity (13). 
High mobility group box 1 (HMGB1) and the receptor for advanced glycation end products (RAGE) are crucial for tumor progression, drug resistance, and metastasis in pancreatic adenocarcinoma $(14,15)$. Accumulating evidence suggests that RAGE expression is elevated in pancreatic cancer and pancreatic cancer cell lines but not in adjacent normal epithelial tissue $(16,17)$. Moreover, our previous study found that RAGE/HMGB1 upregulates the expression of MDR1 in GEM-resistant MiaPaCa-2 (MiaPaCa-2 ${ }^{\text {GEMR }}$ ) cells (18-20). This indicates that RAGE/HMGB1 plays a crucial role in pancreatic cancer progression and chemoresistance. However, the roles of 4-AAQB in suppressing pancreatic cancer and enhancing GEM chemosensitivity remain unclear. The aim of this study was to investigate the underlying mechanisms of cytotoxicity and enhanced chemosensitivity mediated by 4-AAQB treatment in human pancreatic cancer $\mathrm{MiaPaCa}-2$ and MiaPaCa-2 $2^{\text {GEMR }}$ cells.

\section{Materials and methods}

Chemicals. 4-Acetylantroquinonol B (4-AAQB) was kindly provided by Grape King Bio Ltd. Sodium bicarbonate $\left(\mathrm{NaHCO}_{3}\right), 2^{\prime}, 7^{\prime}$-dichlorofluorescein diacetate (DCFH-DA), penicillin-streptomycin solution (PS), MTT, DMSO, TEMED, SDS, glycine, Tris, isopropanol, Tween-20, bovine serum albumin (BSA), Triton X-100, sodium chloride $(\mathrm{NaCl})$, and GEM were purchased from MilliporeSigma. Propidium iodide (PI) and Annexin V staining kit (cat. no. 559763) was purchased from BD Biosciences. BCA protein assay kit (BC03-500) was purchased from Energenesis Biomedical. $\beta$-actin (cat. no. NB600-501), Beclin-1 (cat. no. NB110-87318), vascular endothelial growth factor-A (cat. no. VEGFA, NB100-664), LC3 II (cat. no. NB100-2220), and Atg5 (cat. no. NB110-53818) antibodies were purchased from Novus Biologicals. Bax (cat. no. 5023), Bcl-xL (cat. no. 2762), PI3K (cat.no. 4292), phospho-PI3K (cat. no. 4228), Akt (cat. no. 9272), phospho-Akt (cat. no. 9271), HMGB1, PI3K catalytic subunit type III (Vps34; cat. no. 4263), and MDR1 (cat. no. 6893) antibodies were obtained from Cell Signaling Technology, Inc. The anti-RAGE (cat. no. PA5-24787) antibody was purchased from Invitrogen (Thermo Fisher Scientific, Inc.). Dulbecco's modified eagle medium (DMEM) high glucose medium, fetal bovine serum (FBS), and horse serum were purchased from Gibco (Thermo Fisher Scientific, Inc.).

Cell culture. The Homo sapiens pancreatic cancer cell line MiaPaCa-2 was purchased from the Bioresource Collection and Research Center (Hsinchu, Taiwan). The GEM-resistant MiaPaCa-2 ${ }^{\text {GEMR }}$ cell line was established by gradually increasing GEM concentrations to $0.5 \mu \mathrm{M}$ GEM to induce tolerance as described in a previous report (21). Cells were cultured in DMEM (high glucose) medium supplemented with $10 \%$ fetal bovine serum (FBS) plus $2.5 \%$ horse serum and $1 \% \mathrm{PS}$ antibiotic solution $(100 \mathrm{U} / \mathrm{ml}$ penicillin and $100 \mu \mathrm{g} / \mathrm{ml}$ streptomycin). The two cell lines were maintained in a $37^{\circ} \mathrm{C}$ incubator with $5 \% \mathrm{CO}_{2}$.

Cell viability. MiaPaCa-2 and MiaPaCa-2 $2^{\text {GEMr }}$ cells $\left(8 \times 10^{3}\right.$ cells/well) were cultured in a 96 -well plate overnight. The cells were incubated with various concentrations
$(0.1-5 \mu \mathrm{M})$ of $4-\mathrm{AAQB}$ at $37^{\circ} \mathrm{C}$ for $48 \mathrm{~h}$. The medium was discarded, and the cells were washed in PBS three times. Cells were incubated with MTT solution $(0.5 \mathrm{mg} / \mathrm{ml})$ for $1 \mathrm{~h}$ at $37^{\circ} \mathrm{C}$. The MTT solution was removed and the formazan crystals were dissolved in $200 \mu \mathrm{l}$ DMSO. Cell viability was determined using a microplate reader (FLUOstar Omega) at $570 \mathrm{~nm}$ and calculated as: Cell viability $(\%)=$ Absorbance of the sample/Absorbance of the control) x100.

Reactive oxygen species (ROS) measurement. MiaPaCa-2 and $\mathrm{MiaPaCa}-2^{\text {GEMR }}$ cells $\left(6 \times 10^{4}\right.$ cells/well) were cultured in a 24-well plate overnight. Cells were treated with 4-AAQB ( 2 and $5 \mu \mathrm{M}$ ) with or without GEM at $37^{\circ} \mathrm{C}$ for $48 \mathrm{~h}$. The cells were then incubated with DCFH-DA at $37^{\circ} \mathrm{C}$ for $30 \mathrm{~min}$. The cellular ROS level was measured using a Fluostar Galaxy reader (BMG Labtechnologies Ltd.) with maximum excitation and emission spectra of 485 and $520 \mathrm{~nm}$, respectively. The level of ROS was calculated as the rate of change in contrast to the level in untreated cells.

Cell cycle analysis. MiaPaCa-2 and MiaPaCa-2 $2^{\mathrm{GEMR}}$ cells $\left(6 \times 10^{4}\right.$ cells $\left./ \mathrm{ml}\right)$ were cultured in a 6 -well plate overnight. Cells were incubated with various concentrations ( 2 and $5 \mu \mathrm{M})$ of 4-AAQB at $37^{\circ} \mathrm{C}$ for $48 \mathrm{~h}$. The medium was discarded and cells were washed with PBS three times. Cells were harvested by trypsinization and fixed with $70 \%$ ethanol at $-20^{\circ} \mathrm{C}$ for $2 \mathrm{~h}$. Cells $\left(1 \times 10^{5}\right)$ were stained with $0.5 \mathrm{ml} \mathrm{PI/RNase}$ staining buffer (cat. no. 550825, BD Biosciences) at room temperature for $30 \mathrm{~min}$. The cell cycle was evaluated using a BD Accuri C6 Plus flow cytometer (BD Biosciences). The cell cycle phase distribution was analyzed by ModFit LT 3.1 software (Verity Software House).

Annexin $V$ and PI staining. MiaPaCa-2 and MiaPaCa- $2^{\text {GEMR }}$ cells $\left(6 \times 10^{4}\right.$ cells $\left./ \mathrm{ml}\right)$ were cultured in a 6 -well plate overnight. Cells were incubated with 4 -AAQB $(2$ and $5 \mu \mathrm{M})$ at $37^{\circ} \mathrm{C}$ for $48 \mathrm{~h}$, double-stained with Annexin V and PI at room temperature for $15 \mathrm{~min}$ and analyzed using a BD Accuri C6 Plus flow cytometer (BD Biosciences). Quadrant 1 (negative for Annexin V and PI) indicates living cells, quadrant 2 (Annexin V-positive, PI-negative) indicates early apoptotic cells, quadrant 3 (positive for Annexin V and PI) indicates the late apoptotic cells, and quadrant 4 (Annexin V-negative, PI-positive) indicates necrotic cells. The data was analyzed by ModFit LT 3.1 software (Verity Software House).

Western blot analysis. MiaPaCa-2 and MiaPaCa-2 $2^{\text {GEMR }}$ cells $\left(1 \times 10^{6}\right)$ were incubated with 4 -AAQB $(2$ and $5 \mu \mathrm{M})$ at $37^{\circ} \mathrm{C}$ for $48 \mathrm{~h}$. The expression of proteins related to apoptosis (Bcl-xL and Bax), autophagy (Atg5, Beclin-1, and LC3 II), and GEM resistance-associated signaling (PI3K, phospho-PI3K, Akt, phospho-Akt, Vps34, RAGE, HMGB1, and MDR1) was determined using western blotting as described in a previous report (21). Briefly, cells were lysed by ice-cold RIPA lysis buffer (Thermo Fisher Scientific, Inc.) containing a cocktail of $1 \%$ protease inhibitors (P\&C Biotech, Inc.) and 1\% phosphatase inhibitors ( $\mathrm{P} \& \mathrm{C}$ Biotech, Inc.), and the protein concentration was determined using a BCA protein assay kit (Energenesis Biomedical Co., Ltd.) according to the user guide. A total of $50 \mu \mathrm{g}$ protein per lane was separated using 
10-12\% SDS-PAGE, then transferred to PVDF membranes and blocked with 5\% non-fat milk in TBS-0.1\% Tween-20 (TBST) at room temperature for $1 \mathrm{~h}$. PVDF membranes were incubated primary antibodies $(1: 1,000)$ overnight at $4^{\circ} \mathrm{C}$. After washing three times with TBST at room temperature for $10 \mathrm{~min}$, the membranes were incubated HRP-conjugated secondary antibodies $(1: 10,000)$ at room temperature for $2 \mathrm{~h}$. After antibody incubation, the protein was visualized using the ECL detecting reagent (PerkinElmer, Inc.), and the density of the target protein bands was quantified with the corresponding internal reference proteins by the Biospectrum 810 UVP VisionWorks LS Image Acquisition and Analysis Software (UVP).

Chemosensitivity analysis. MiaPaCa-2 and MiaPaCa- $2^{\text {GEMR }}$ cells $\left(4 \times 10^{4}\right.$ cells $\left./ \mathrm{ml}\right)$ were cultured in a 96 -well plate overnight. The increase in chemosensitivity was evaluated through both cotreatment with 4-AAQB and GEM and 4-AAQB pretreatment methods. For cotreatment, cells were incubated with 4-AAQB (2 and $5 \mu \mathrm{M}$ ) plus GEM at $37^{\circ} \mathrm{C}$ for $48 \mathrm{~h}$. For pretreatment, cells were pretreated with 4 -AAQB $(2$ and $5 \mu \mathrm{M})$ at $37^{\circ} \mathrm{C}$ for $48 \mathrm{~h}$ and then incubated with GEM at $37^{\circ} \mathrm{C}$ for another $48 \mathrm{~h}$. In the pretreatment method, cells unexposed to 4-AAQB or GEM were incubated in complete medium until the end of the experiment. After treatments, chemosensitivity was determined using the MTT analysis.

Cell migration assay. Cell migration was evaluated using a gap closure assay. The Ibidi ${ }^{\circledR}$ culture inserts were placed in a 24-well plate, and then MiaPaCa-2 and MiaPaCa-2 ${ }^{\text {GEMR }}$ cells $\left(5 \times 10^{5}\right.$ cells $\left./ \mathrm{ml}\right)$ were seeded into the inserts and cultured with complete medium overnight. After cell attachment, the culture insert was removed and then the migration distance was recorded after exposure to 4-AAQB (2 and $5 \mu \mathrm{M})$ with or without $\operatorname{GEM}(0.5 \mu \mathrm{M})$ at $37^{\circ} \mathrm{C}$ for $48 \mathrm{~h}$ in serum free condition. The cell migration rate was calculated using ImageJ software (version 1.34s; National Institutes of Health). The migration area of the various treatment groups was calculated as a percentage of the untreated group using the following formula: Mean migration area of the experimental group/mean migration area of the control group x $100 \%$.

Cell invasion assay. Cell invasion was measured using a Transwell ${ }^{\circledR}$ system with an $8-\mu \mathrm{m}$ pore size (Corning, Inc.) as described previously (22). Briefly, $0.5 \mathrm{mg} / \mathrm{ml}$ Matrigel (Thermo Fisher Scientific, Inc.) was coated on the upper chambers of the inserts at $37^{\circ} \mathrm{C}$ for $1 \mathrm{~h}$. MiaPaCa-2 and MiaPaCa- $2^{\text {GEMR }}$ cells $\left(5 \times 10^{4}\right.$ cells/well) were cultured with 4-AAQB (2 and $5 \mu \mathrm{M}$ ) under serum-free conditions at $37^{\circ} \mathrm{C}$ for $48 \mathrm{~h}$ on the upper chambers and medium containing $10 \%$ FBS served as a chemoattractant in the lower chambers. The invading cells were subsequently fixed in $100 \%$ methanol for $10 \mathrm{~min}$ at room temperature, stained with $0.5 \%$ crystal violet for $10 \mathrm{~min}$ at room temperature. The total invasive number of cells was calculated using the Power IX71 Inverted Fluorescence Microscope (Olympus Corporation).

Statistical analysis. All experiments were repeated independently three times. The data were analyzed using one-way ANOVA followed by Tukey's post hoc test using the SPSS 20 software (IBM, Corp.) and are shown as the mean \pm SD. $\mathrm{P}<0.05$ was considered to indicate a statistically significant difference.

\section{Results}

4-AAQB induces cytotoxicity and cell cycle arrest in pancreatic cancer cells. MiaPaCa-2 ${ }^{\mathrm{GEMR}}$ cells were generated to explore the molecular mechanisms of GEM resistance in pancreatic cancer cells (21). The structure of 4-AAQB is shown in Fig. 1A. The effect of 4-AAQB on cell viability was evaluated in both $\mathrm{MiaPaCa}-2$ and $\mathrm{MiaPaCa}-2^{\mathrm{GEMR}}$ cells. Cytotoxicity was significantly increased by $4-\mathrm{AAQB}$ treatment in a dose-dependent manner $(0.1-5 \mu \mathrm{M})$ for $48 \mathrm{~h}$ (Fig. $1 \mathrm{~B}$ and $\mathrm{C}$ ). The $\mathrm{IC}_{50}$ values of $4-\mathrm{AAQB}$ in $\mathrm{MiaPaCa}-2$ and $\mathrm{MiaPaCa}-2^{\mathrm{GEMR}}$ cells were 1.61 and $3.8 \mu \mathrm{M}$, respectively (Fig. 1B and C). Doses of 2 and $5 \mu \mathrm{M}$ were used in subsequent experiments

Cell viability is directly affected by cell cycle arrest, apoptosis, and autophagy in cancer cells (18). S-phase cell cycle arrest was observed in $\mathrm{MiaPaCa}-2$ cells subjected to 4-AAQB treatment, whereas the percentage of G0/G1 phase cells was significantly reduced in 4-AAQB-treated MiaPaCa-2 cells compared with untreated MiaPaCa-2 cells (Fig. 1D). In addition, this coordinated change in $\mathrm{G} 2 / \mathrm{M}$ cell cycle arrest was observed in 4-AAQB-treated MIAPaCa-2 ${ }^{\text {GEMR }}$ cells (Fig. 1E). Previous studies have found that cell cycle regulators not only influence cell division but also induce programmed cell death (23). In the present study, treatment with 4-AAQB led to dose-dependent cell cycle arrest, suggesting that 4-AAQB treatment may inhibit cell cycle progression in pancreatic cancer cells.

4-AAQB treatment promotes apoptosis and inhibits autophagy. Emerging evidence suggests that to increase apoptosis and decrease autophagy are powerful therapeutic strategies for pancreatic cancer progression (24). In the present study, the percentage of late apoptotic cells was significantly induced in a dose-dependent manner following 4-AAQB treatment in both cell lines (Fig. 2). Western blot analysis was used to examine the expression of apoptosis-associated proteins. Consistent with published evidence (24), although the levels of Bcl-xL were not significantly altered by $2 \mu \mathrm{M} 4-\mathrm{AAQB}$ treatment, however, it was significantly reduced following $5 \mu \mathrm{M}$ 4-AAQB treatment in MiaPaCa-2 ${ }^{\mathrm{GEMR}}$ cells compared with the untreated cells (Fig. 3A and B). The levels of Bax significantly increased in $\mathrm{MiaPaCa}-2^{\mathrm{GEMR}}$ cells treated with 4-AAQB (Fig. 3A and C). Moreover, the Bax/Bcl-xL ratio significantly increased in $5 \mu \mathrm{M}$ 4-AAQB-treated MiaPaCa-2 and MiaPaCa-2 $2^{\text {GEMR }}$ cells (Fig. 3D).

The pro-apoptotic protein Bax directly inhibits autophagy (25). Furthermore, clinical evidence has revealed that autophagy is involved in resistance to gemcitabine/nab-paclitaxel chemotherapy and its cytotoxic response in patients with pancreatic cancer (26). Thus, the expression levels of autophagy-associated proteins (Atg5, Beclin-1 and LC3 II) were assessed using western blotting. The protein expression levels of Atg5 and LC3 II were significantly reduced after 4-AAQB treatment in both cell lines compared with the untreated cells (Fig. 4). 


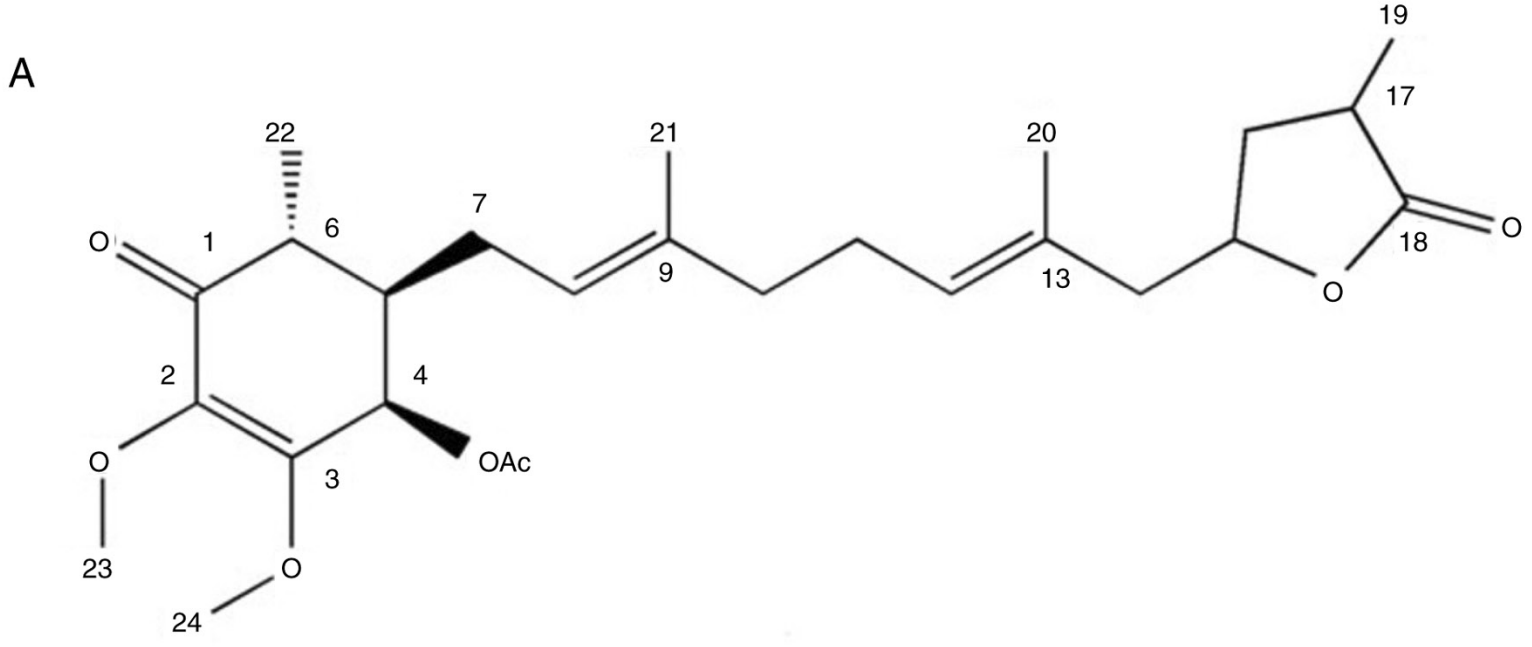

B

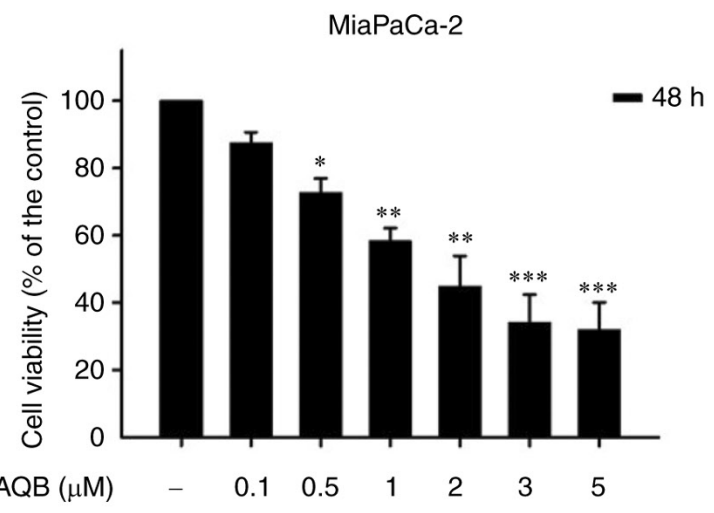

C

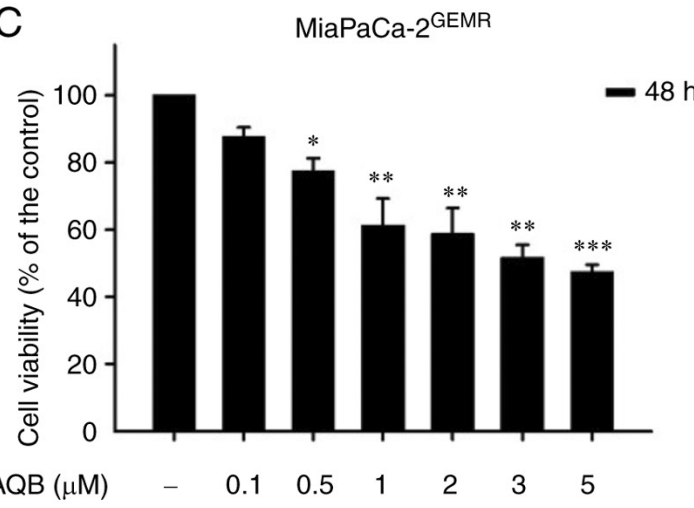

D

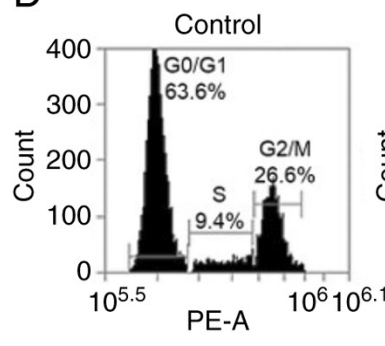

E

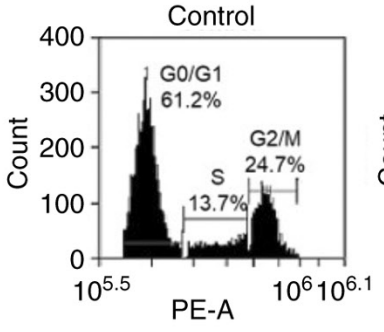

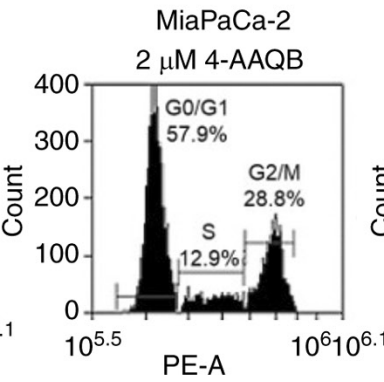

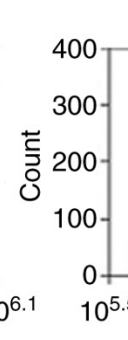

10.5

$5 \mu \mathrm{M} 4-\mathrm{AAQB}$
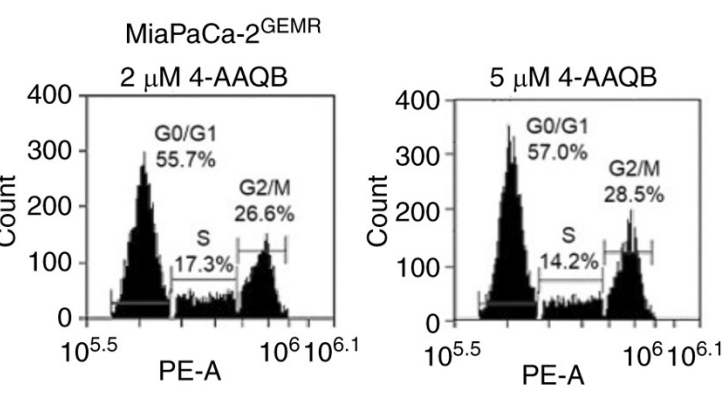

PE-A

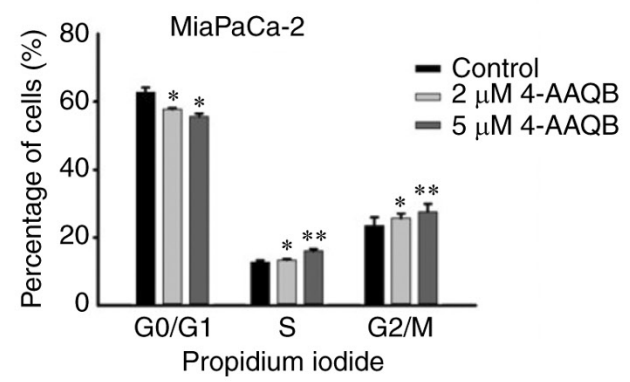

$10^{6} 10^{6}$

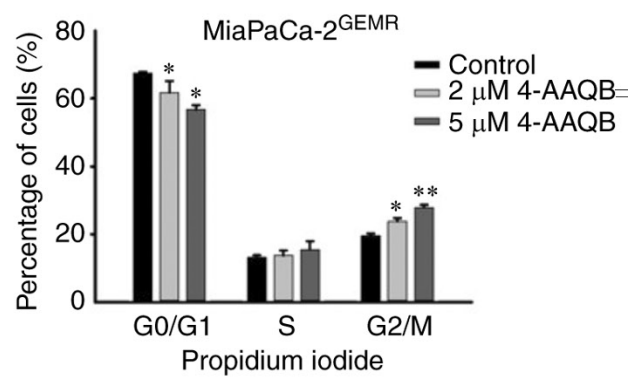

Figure 1. 4-AAQB treatment inhibits cell cycle progression and viability. (A) Structure of 4-AAQB. (B) MiaPaCa-2 and (C) MiaPaCa-2 ${ }^{\mathrm{GEMR}}$ cell viability was determined using MTT assays. Cell cycle analysis of (D) MiaPaCa-2 and (E) MiaPaCa-2 ${ }^{\text {GEMR }}$ cells was carried out using flow cytometry. ${ }^{*} \mathrm{P}<0.05,{ }^{* *} \mathrm{P}<0.01$, and ${ }^{* * *} \mathrm{P}<0.001$ vs. the untreated control cells. 4-AAQB, 4-Acetylantroquinonol B; GEMR, gemcitabine-resistant.

The PI3K/Akt signaling pathway is critical for tumor survival and autophagy initiation $(27,28)$. The phosphorylation of PI3K and Akt significantly decreased in 4-AAQB-treated
MiaPaCa-2 and MiaPaCa-2 $2^{\mathrm{GEMR}}$ cells compared with untreated cells (Fig. 5A-C). Vps34 binds to beclin-1 and subsequently activates autophagy (29). Additionally, a previous 

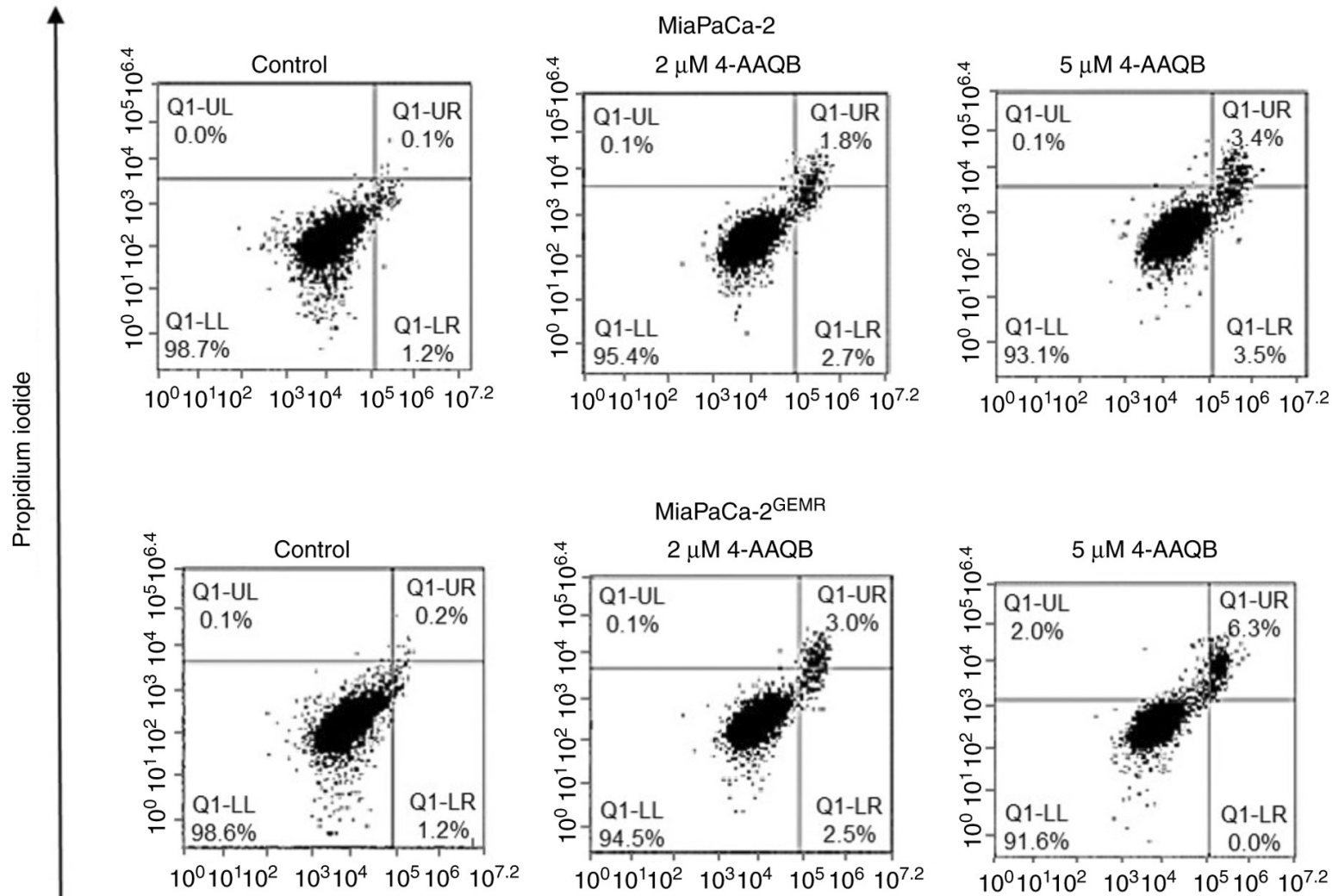

Annexin V-FITC
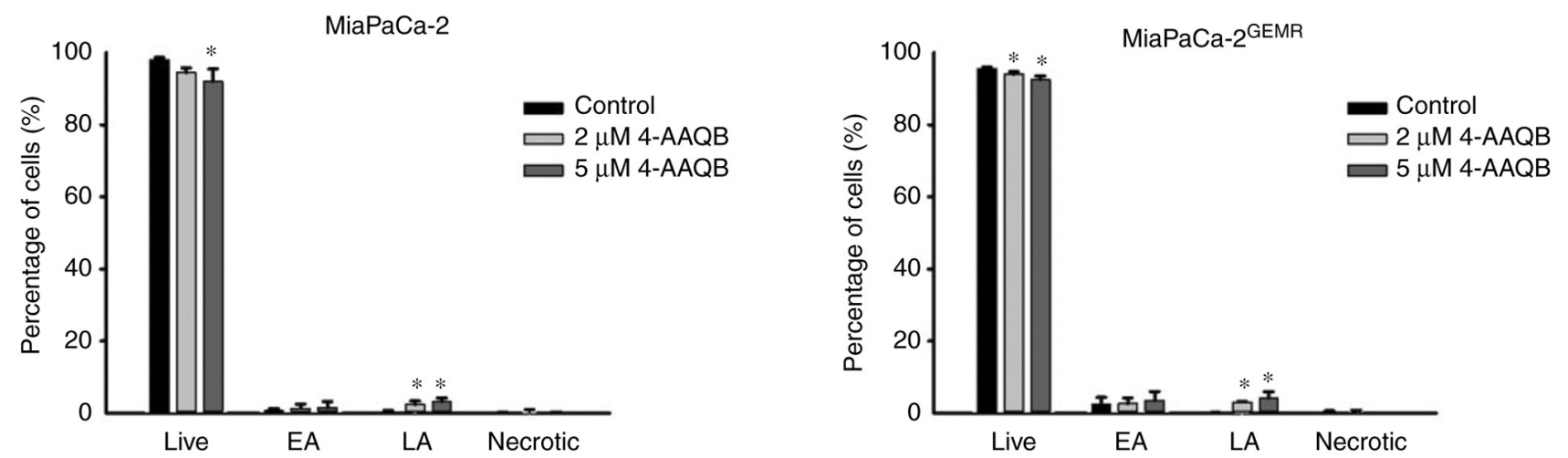

Figure 2. 4-AAQB promotes apoptosis in MiaPaCa-2 and MiaPaCa-2 $2^{\mathrm{GEMR}}$ cells. The cells were treated with the indicated concentrations of 4-AAQB for $48 \mathrm{~h}$. Annexin V/propidium iodide staining was carried out to detect apoptotic cells using flow cytometry. " $\mathrm{P}<0.05$ vs. the untreated control cells. $4-\mathrm{AAQB}$, 4-Acetylantroquinonol B; GEMR, gemcitabine-resistant; FITC, fluorescein isothiocyanate; EA, early apoptosis; LA, late apoptosis.

study indicated that VPS34 was essential for the autophagy process (30). In the present study, the expression of the Vps34 protein was significantly reduced following the 4-AAQB incubation in both cell lines (Fig. 5D and E).

Chemosensitivity and ROS levels are enhanced through the suppression of the RAGE-HMGBI-initiated $P I 3 K / A k t / M D R 1$ signaling axis in both cell lines treated with 4-AAQB. As shown in our previous study, the $\mathrm{PI} 3 \mathrm{~K} / \mathrm{Akt} / \mathrm{MDR} 1$ axis is triggered by HMGB1 and RAGE engagement during GEM chemoresistance (19). Thus, the protein expression levels of HMGB1, RAGE, and MDR1 were examined. The levels of HMGB1 and RAGE were significantly inhibited after $5 \mu \mathrm{M} 4$-AAQB treatment in
MiaPaCa-2 cells (Fig. 6A-C). Moreover, treatment with both 2 and $5 \mu \mathrm{M} 4$-AAQB effectively inhibited HMGB1 and RAGE expression in MiaPaCa-2 ${ }^{\text {GEMR }}$ cells (Fig. 6A-C). Accordingly, the level of the MDR1 protein was reduced by 4-AAQB treatment in a dose-dependent manner in both cell lines (Fig. 6D and E).

A previous study showed that suppression of the PI3K/AKT pathway by inducing ROS generation may represent a strategy for cancer treatment (31). Additionally, GEM induces ROS, resulting in an increase in pancreatic cancer cell death, although the opposite effect is observed in GEM-resistant cells (32). In the present study, ROS levels were measured using DCFH-DA staining. The results showed that ROS levels significantly increased in a dose-dependent manner following 4-AAQB treatment in both cell 
A

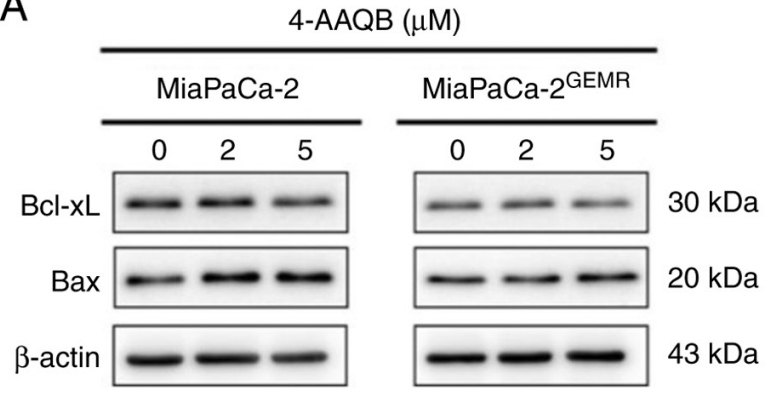

B

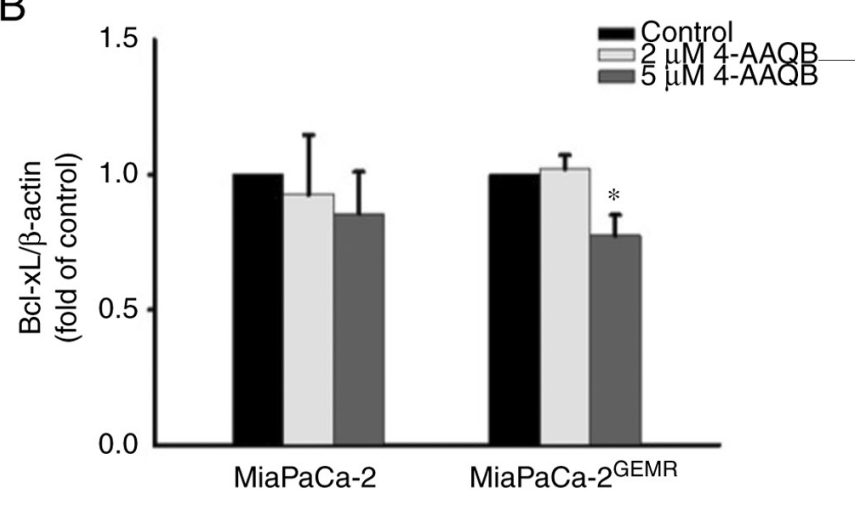

D

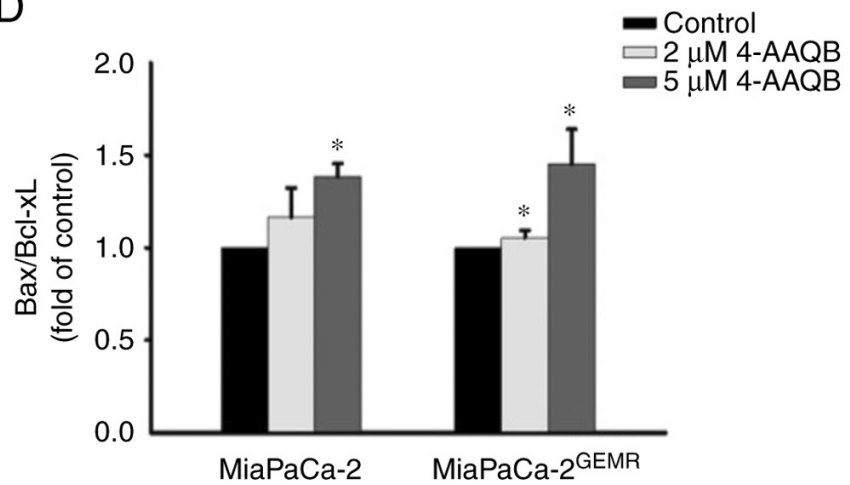

Figure 3. 4-AAQB upregulates the expression of apoptosis-associated proteins in MiaPaCa-2 and MiaPaCa-2 $2^{\mathrm{GEMR}}$ cells. The cells were treated with the indicated concentrations of 4-AAQB for $48 \mathrm{~h}$. (A) The expression levels of apoptosis-associated proteins (Bcl-xL and Bax) were assessed using western blotting. (B and C) Semi-quantification of Bcl-xL and Bax protein expression. (D) Bax/Bcl-xL ratio. "P<0.05 vs. the untreated control cells. 4-AAQB, 4-Acetylantroquinonol B; GEMR, gemcitabine-resistant.

A

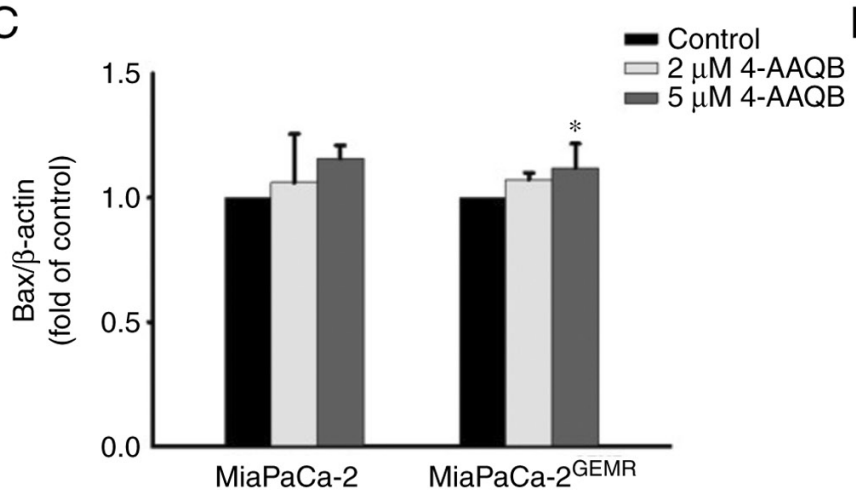

$\mathrm{B}$

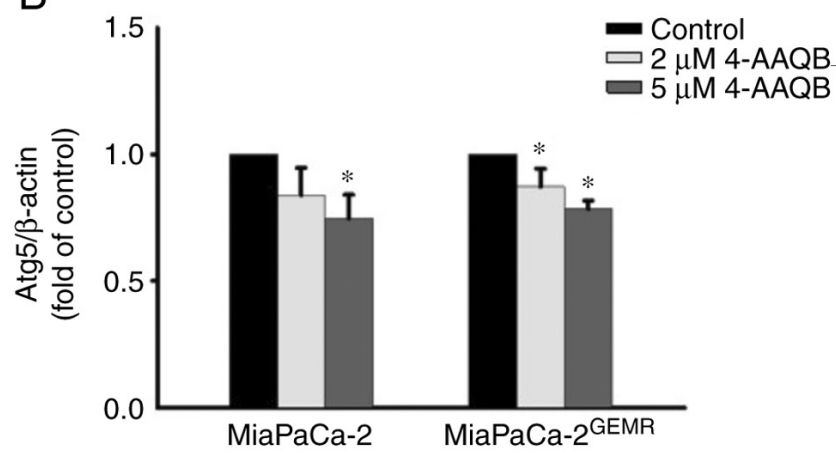

$\mathrm{D}$

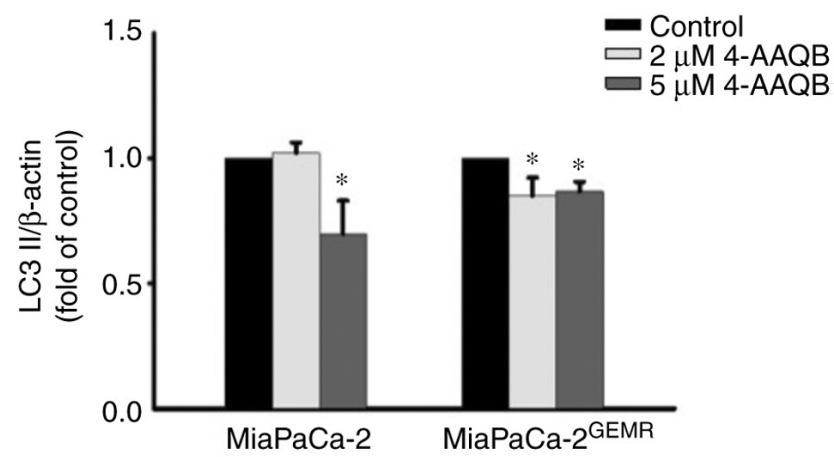

Figure 4. 4-AAQB treatment downregulates the levels of autophagy-associated proteins in MiaPaCa-2 and MiaPaCa-2 ${ }^{\mathrm{GEMR}}$ cells. (A) The expression of Atg5, Beclin-1 and LC3 II was analyzed using western blotting. (B-D) Semi-quantification of Atg5, Beclin-1 and LC3 II protein levels. * $<<0.05$ vs. the untreated control cells. 4-AAQB, 4-Acetylantroquinonol B; GEMR, gemcitabine-resistant; Atg5, autophagy-related 5. 

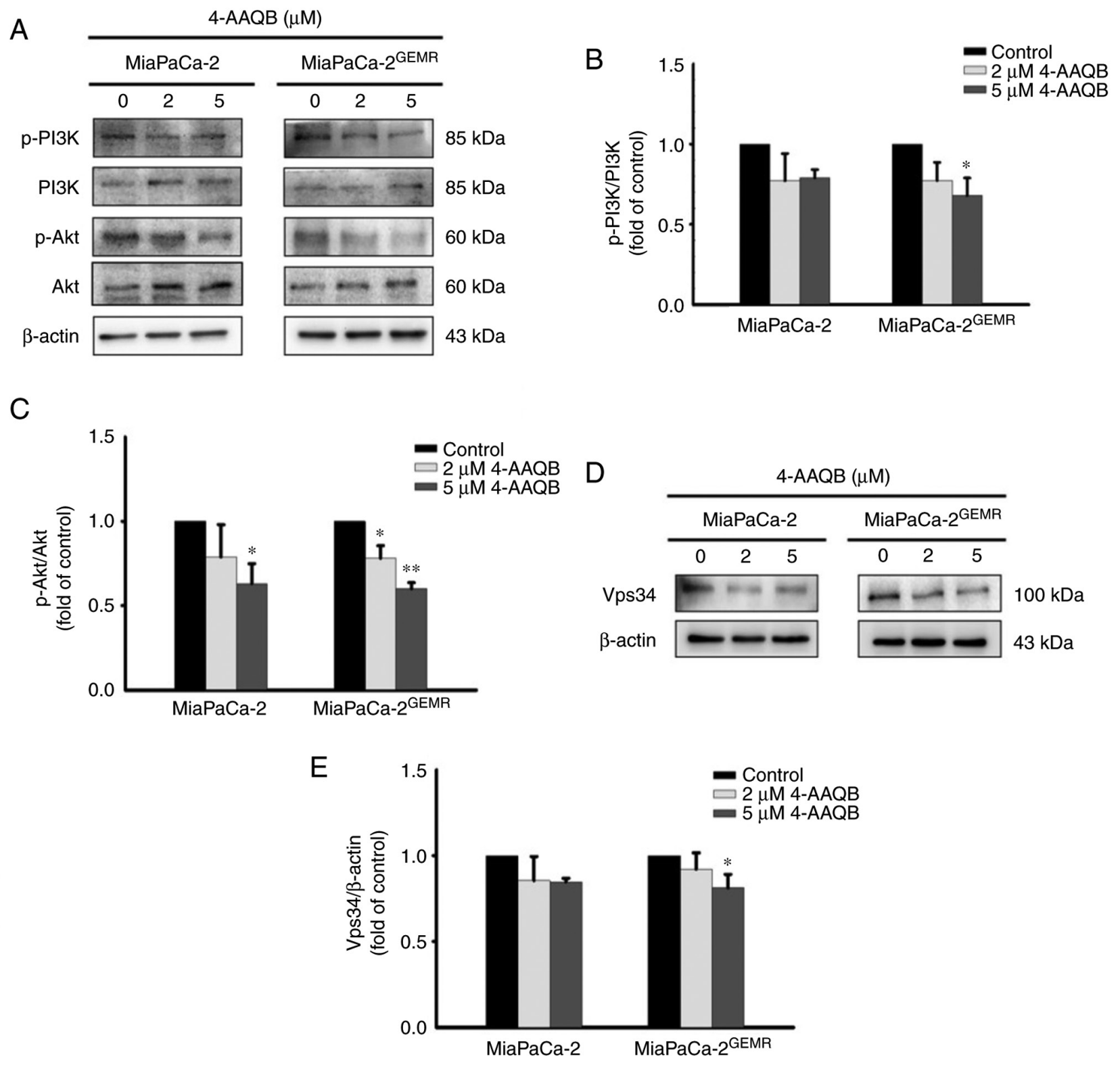

Figure 5. 4-AAQB downregulates the expression of the PI3K, Akt and Vps34 proteins in MiaPaCa-2 and MiaPaCa-2 ${ }^{\mathrm{GEMR}}$ cells. (A) The levels of P-PI3K, PI3K, p-Akt and Akt were analyzed using western blotting. (B) Semi-quantification of p-PI3K/PI3K protein levels. (C) Semi-quantification of p-Akt/Akt protein levels. (D) The expression of Vps34 was analyzed using western blotting. (E) Semi-quantification of Vps34 protein levels. ${ }^{*} \mathrm{P}<0.05$ and ${ }^{* * *} \mathrm{P}<0.01$ vs. the untreated control cells. 4-AAQB, 4-Acetylantroquinonol B; GEMR, gemcitabine-resistant; p-, phosphorylated; Vps34, phosphatidylinositol 3-kinase catalytic subunit type 3 .

lines (Fig. 7A and B). Notably, ROS accumulation was dramatically increased by 4-AAQB combination with GEM treatment in MiaPaCa-2 ${ }^{\text {GEMR }}$ cells compared with 4-AAQB-treated alone or GEM-treated alone condition (Fig. 7B).

Pancreatic cancer is highly malignant with great metastatic capacity (33). An increase in chemosensitivity is important for preventing the local invasion and long distant metastasis of pancreatic cancer (34). The ability of 4-AAQB to increase chemosensitivity was evaluated using 4-AAQB cotreatment with GEM and 4-AAQB pretreatment methods in both cell lines to select an effective drug treatment pattern. Consistent with the results presented in Fig. 1B, cell viability was significantly reduced by GEM and 4-AAQB (2 and $5 \mu \mathrm{M})$ treatment in MiaPaCa-2 cells compared with untreated cells (Fig. 8A). Compared with GEM treatment, chemosensitivity was effectively enhanced following 4-AAQB cotreatment with GEM in MiaPaCa-2 cells (Fig. 8A). Cell viability was not altered following $0.5 \mu \mathrm{M}$ GEM treatment in MiaPaCa- $2^{\mathrm{GEMR}}$ cells (Fig. 8B), indicating that the GEM-resistant pancreatic cancer cell lines was successfully established. Cell viability was significantly reduced both by 4 -AAQB treatment alone and by 4-AAQB/GEM co-treatment in cells (Fig. 8B). In addition, the effect of the 4-AAQB pre-treatment on enhancing chemosensitivity was also evaluated. Cells were pretreated with 4-AAQB for $48 \mathrm{~h}$, then incubated with GEM for another $48 \mathrm{~h}$. In MiaPaCa-2 cells, the GEM and 4-AAQB (2 and $5 \mu \mathrm{M}$ ) treatment significantly reduced cell viability (Fig. 8C). Additionally, chemosensitivity was significantly increased following 4-AAQB pre-treatment in MiaPaCa-2 cells compared with GEM-treated cells (Fig. 8C). In addition, 
A

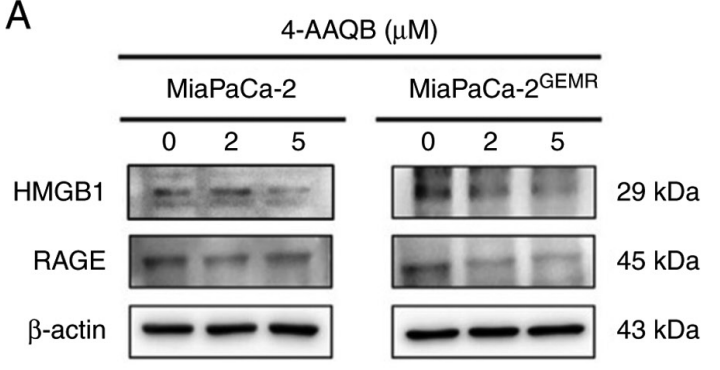

C

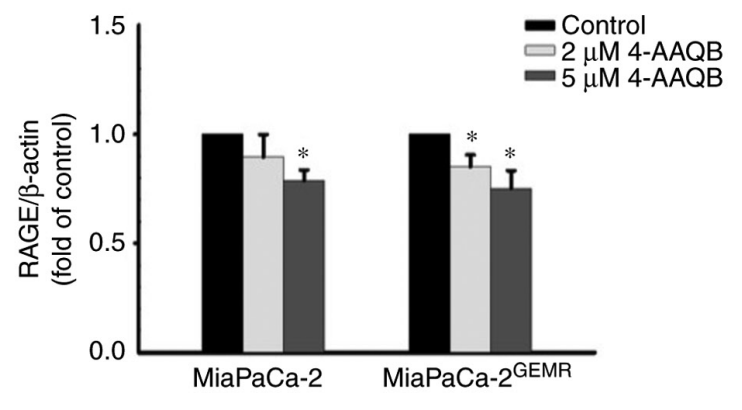

$\mathrm{B}$

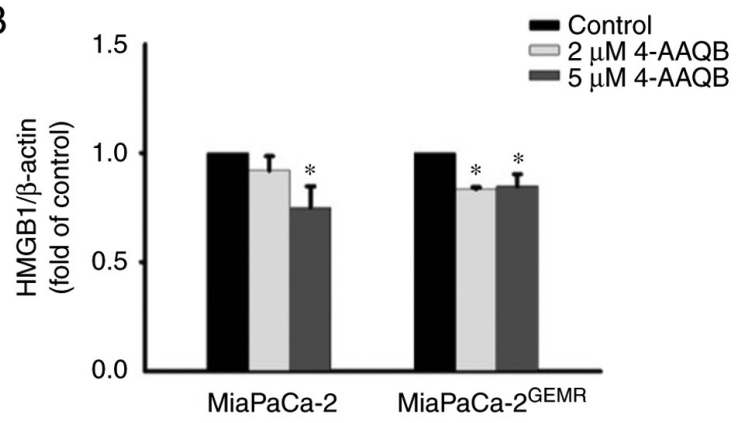

D

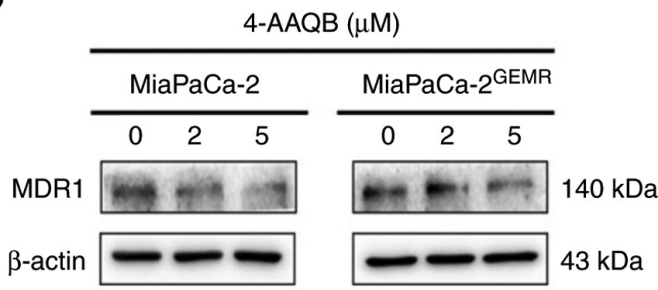

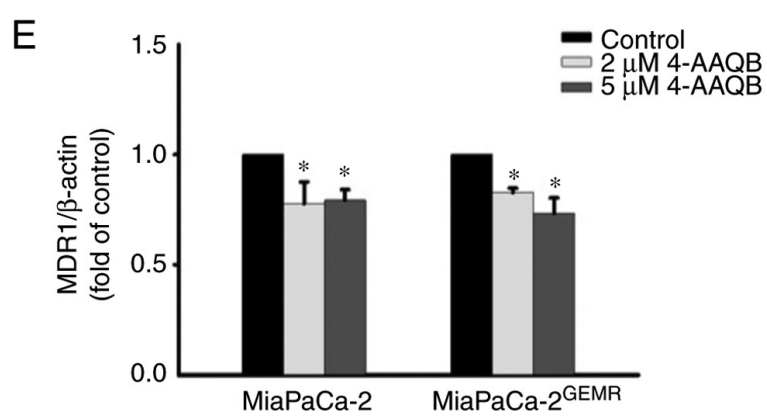

Figure 6. 4-AAQB treatment downregulates HMGB1, RAGE and MDR1 protein expression. (A) The expression of HMGB1 and RAGE was analyzed using western blotting. (B and C) Semi-quantification of HMGB1 and RAGE protein levels. (D) The expression of MDR1 was analyzed using western blotting. (E) Semi-quantification of MDR1 protein levels. * $\mathrm{P}<0.05$ vs. the untreated control cells. 4-AAQB, 4-Acetylantroquinonol B; GEMR, gemcitabine-resistant; HMGB1, high mobility group box 1 protein; MDR1, multidrug resistance protein 1; RAGE, receptor for advanced glycation end-products.

A

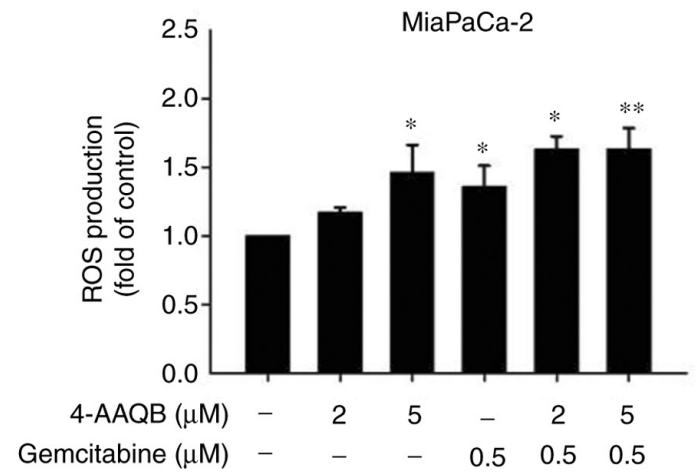

B

$48 \mathrm{~h}$

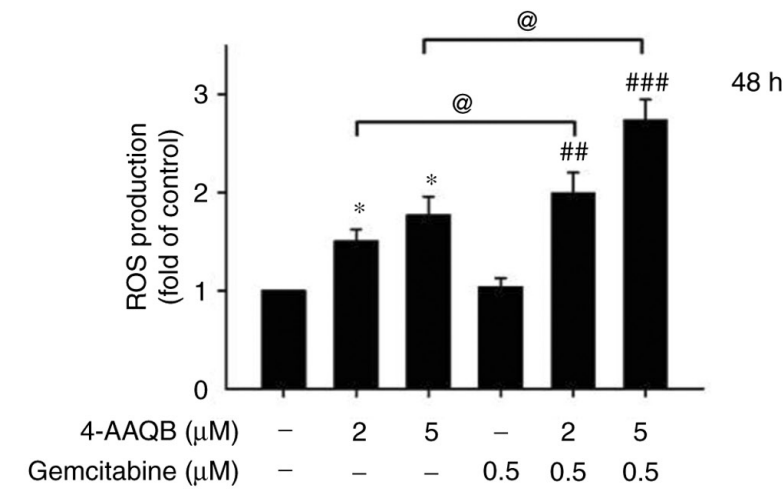

Figure 7. 4-AAQB treatment leads to cellular ROS accumulation. MiaPaCa-2 and MiaPaCa- $2^{\mathrm{GEMR}}$ cells were treated with the indicated concentrations of 4-AAQB and GEM for $48 \mathrm{~h}$. The ROS levels of (A) MiaPaCa-2 and (B) MiaPaCa-2 ${ }^{\mathrm{GEMR}}$ cells were measured using a DCFH-DA probe. $\mathrm{P}<0.05$ and ${ }^{* * *} \mathrm{P}<0.01 \mathrm{vs}$. the untreated control cells; ${ }^{\# \#} \mathrm{P}<0.01$ and ${ }^{\# \# \#} \mathrm{P}<0.001$ vs. the gemcitabine treated cells; ${ }^{\circledR} \mathrm{P}<0.05$ vs. the 4-AAQB treated cells. 4-AAQB, 4-Acetylantroquinonol B; GEMR, gemcitabine-resistant; ROS, reactive oxygen species.

cell viability was significantly inhibited following 4-AAQB ( 2 and $5 \mu \mathrm{M}$ ) pre-treatment with or without GEM incubation in MiaPaCa-2 ${ }^{\text {GEMR }}$ cells (Fig. 8D).
4-AAQB treatment effectively repressed VEGFA-mediated cell migration and invasion. VEGFA plays important roles in cell proliferation, angiogenesis, migration, invasion, 
Co-treatment
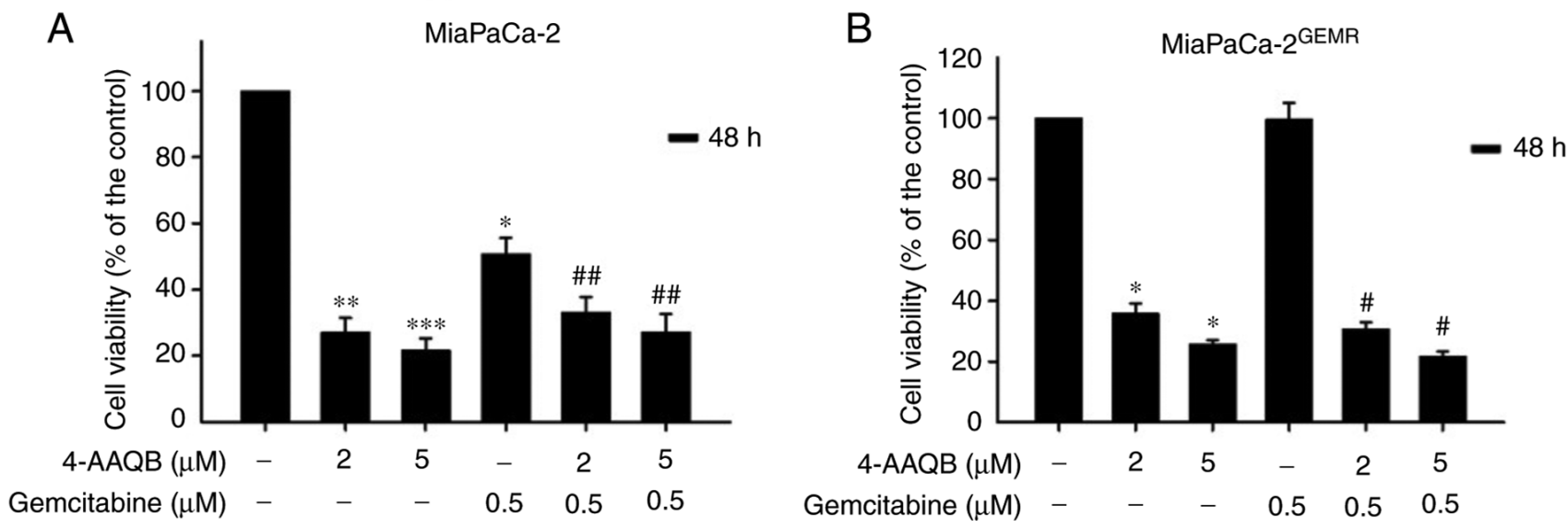

Pre-treatment
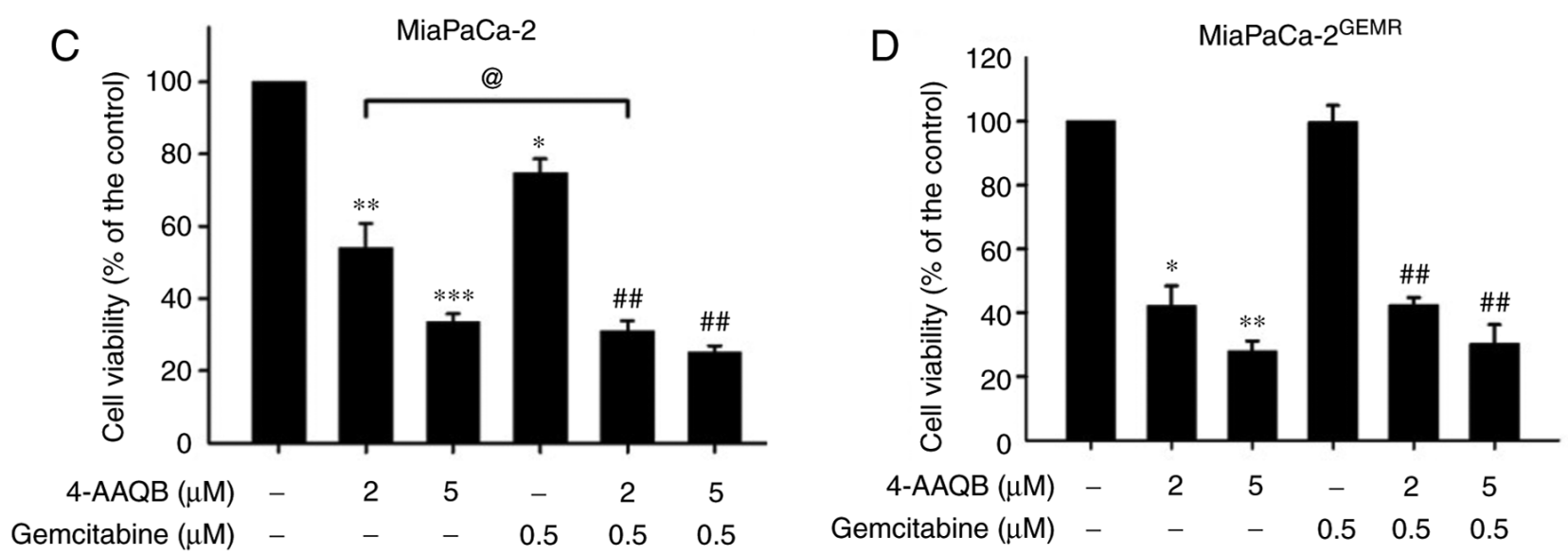

Figure 8. 4-AAQB enhances chemosensitivity to gemcitabine. (A and B) MiaPaCa-2 and MiaPaCa-2 ${ }^{\text {GEMr }}$ cells were treated with the indicated concentrations of 4-AAQB and GEM for $48 \mathrm{~h}$. The viability of (A) MiaPaCa-2 and (B) MiaPaCa-2 ${ }^{\text {GEMR }}$ cells was determined using MTT assays. (C and D) The cells were pretreated with 4-AAQB $(2$ and $5 \mu \mathrm{M})$ for $48 \mathrm{~h}$ and then incubated with GEM for another $48 \mathrm{~h}$. The viability of (C) MiaPaCa-2 and (D) MiaPaCa-2 ${ }^{\mathrm{GEMR}}$ cells was determined using MTT assays. ${ }^{*} \mathrm{P}<0.05{ }^{* *} \mathrm{P}<0.01$, and ${ }^{* * * *} \mathrm{P}<0.001$ vs. the untreated control cells; ${ }^{*} \mathrm{P}<0.05$ and ${ }^{\# \#} \mathrm{P}<0.01$ vs. the gemcitabine treated cells; ${ }^{\circledR} \mathrm{P}<0.05$ vs. the 4-AAQB treated cells. 4-AAQB, 4-Acetylantroquinonol B; GEMR, gemcitabine-resistant.

and cancer metastasis (35). According to a previous study, the upregulation of VEGFA in patients with pancreatic cancer is associated with metastatic disease and shorter overall survival (36). The next experiments were carried out to assess whether 4-AAQB treatment was effective at inhibiting VEGFA production and subsequently preventing cell migration and invasion. Interestingly, VEGFA protein levels significantly decreased in both cell lines subjected to 4-AAQB treatment (Fig. 9A and B). Cell migration was inhibited following 4-AAQB, GEM, and 4-AAQB/GEM co-treatment in MiaPaCa-2 cells compared with untreated cells (Fig. 9C and D). Unexpectedly, the cell migration distance was not substantially reduced by 4-AAQB/GEM co-treatment compared to 4-AAQB treatment alone in MiaPaCa-2 cells (Fig. 9C and D). In addition, 4-AAQB (2 and $5 \mu \mathrm{M}$ ) treatment effectively decreased MiaPaCa-2 ${ }^{\text {GEMR }}$ cell migration compared to untreated cells (Fig. 9E and F). Notably, $2 \mu \mathrm{M}$ 4-AAQB/GEM co-treatment significantly decreased cell migration compared to that of 4-AAQB-treated MiaPaCa-2 ${ }^{\text {GEMR }}$ cells (Fig. 9E and F). In addition, the inhibitory effect of 4-AAQB on cell invasion was also evaluated. The cell invasion abilities of MiaPaCa-2 and MiaPaCa-2 ${ }^{\text {GEMR }}$ cells were significantly reduced by 4-AAQB (2 and $5 \mu \mathrm{M})$ treatment (Fig. 10). Notably, 4-AAQB combined with GEM significantly enhanced the inhibition of cell invasion compared with 4-AAQB-treated MiaPaCa-2 cells 1 and MiaPaCa-2 ${ }^{\text {GEMR }}$ cells (Fig. 10B and D).

\section{Discussion}

GEM is known to induce ROS accumulation, cell cycle arrest, and apoptosis $(37,38)$. However, GEM resistance inhibits ROS production and consequently inhibits cell death in pancreatic ductal adenocarcinoma (32). 4-AAQB triggers cell cycle arrest, apoptosis, and DNA damage by suppressing CDK2/CDK4 expression in human breast cancer and hepatocellular carcinoma cells $(11,39)$. The present study also found that 4-AAQB upregulated cell cycle arrest and apoptosis. This suggested that 4-AAQB may play a vital role in regulating cyclin-dependent kinases (CDKs) in pancreatic cancer cells and the cell cycle-related markers such as CDK1, CDK2, CDK4 or CDK5 were not further evaluated; however, this should be further 
A

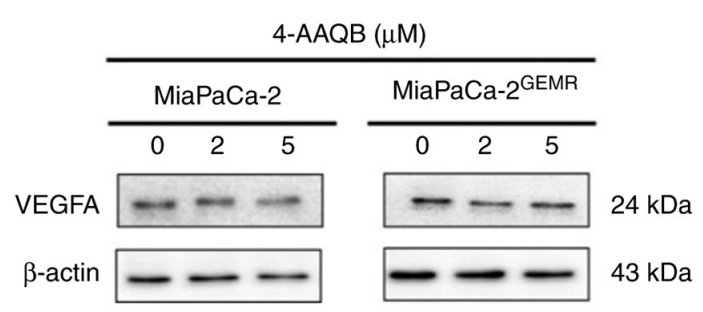

C

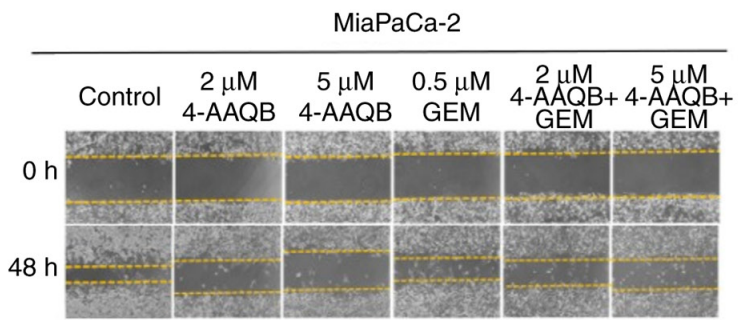

E

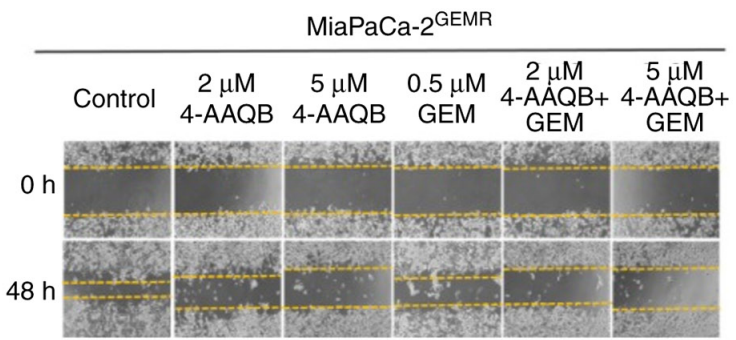

B

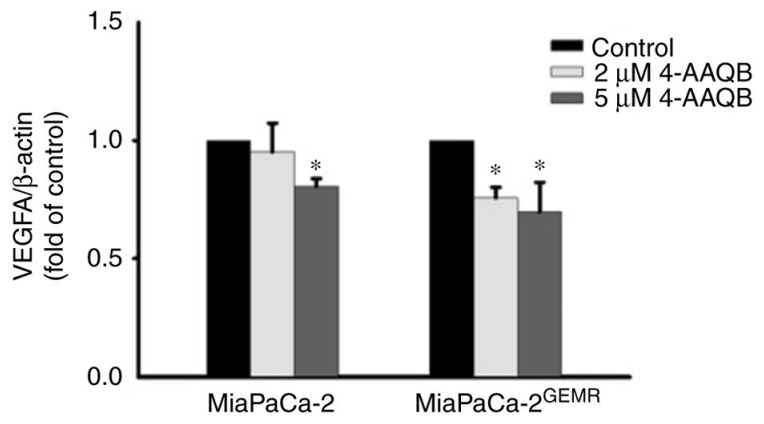

D

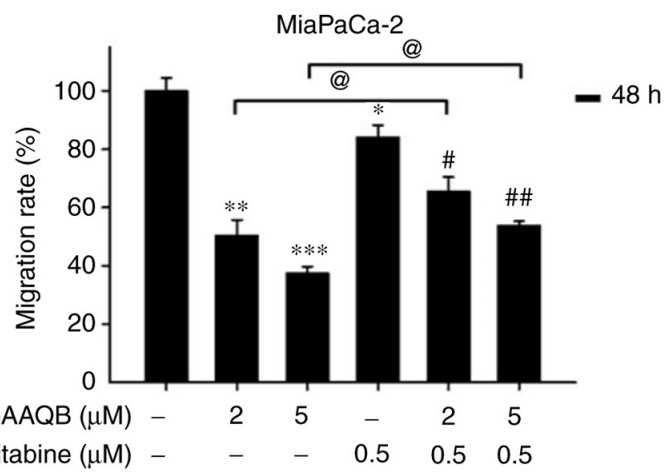

$\mathrm{F}$

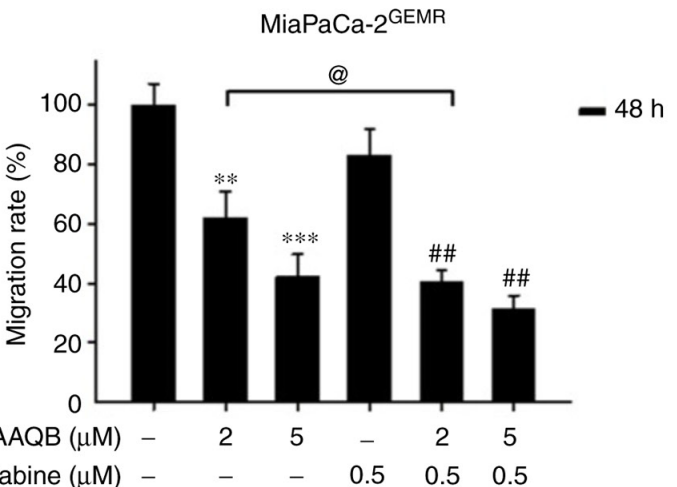

Figure 9. 4-AAQB downregulates VEGFA expression and inhibits cell migration. (A) The expression of the VEGFA protein was analyzed using western blotting. (B) Semi-quantification of VEGFA protein levels. (C and E) Cell migration was assessed using a wound-healing assay. Multiple images were captured of each well at various time points. Magnification, $x 100$. (D and F) The migration distances were recorded and calculated using ImageJ software. ${ }^{*} \mathrm{P}<0.05$ ${ }^{* *} \mathrm{P}<0.01$, and ${ }^{* * *} \mathrm{P}<0.001$ vs. the untreated control cells; ${ }^{*} \mathrm{P}<0.05$ and ${ }^{\# \#} \mathrm{P}<0.01$ vs. the gemcitabine treated cells; ${ }^{\circledR} \mathrm{P}<0.05$ vs. the $4-\mathrm{AAQB}$ treated cells. $4-\mathrm{AAQB}$, 4-Acetylantroquinonol B; GEMR, gemcitabine-resistant.

analyzed in future in vitro studies. Moreover, RAGE downregulation in pancreatic tumor cells is sensitive to $\mathrm{H}_{2} \mathrm{O}_{2}$-induced oxidative injury, indicating that RAGE plays a protective role against oxidative injury $(40,41)$. In the present study, 4-AAQB treatment effectively induced ROS accumulation by inhibiting RAGE/HMG1 levels and promoting cell cycle arrest and apoptosis in both MiaPaCa-2 and GEM-resistant cells. The cumulative evidence suggests 4-AAQB plays an important role the regulation of cancer cell death.

4-AAQB is a novel bioactive compound, and its effect on GEM chemosensitivity remains unclear. A previous study has reported that 4-AAQB plays a critical role in inhibiting tumor growth by attenuating cisplatin chemoresistance and inhibiting Atg5-dependent autophagy in ovarian cancer (42). Increased autophagy in pancreatic cancer is strongly associated with early metastasis and chemotherapy resistance, indicating that autophagy may serve as a therapeutic target for pancreatic cancer (43). Additionally, a clinical trial found that the administration of an autophagy inhibitor (hydroxychloroquine) in combination with GEM therapy effectively increases the survival rate through the activation of immune responses in patients with resectable pancreatic cancer (26). The findings of the present study revealed that autophagy-associated protein (LC3 II and Atg5) levels and GEM resistance were significantly reduced in 4-AAQB-treated cells.

Based on accumulating evidence, apoptosis and autophagy may compete with each other; for example, tioconazole represses autophagy-related 4A cysteine peptidase (ATG4A) and ATG4B expression, which subsequently enhances chemotherapy-induced apoptosis in glioma, colorectal, and breast cancer cells (44). Additionally, spautin-1 (an autophagy inhibitor) has been shown to increase apoptosis by inactivating 

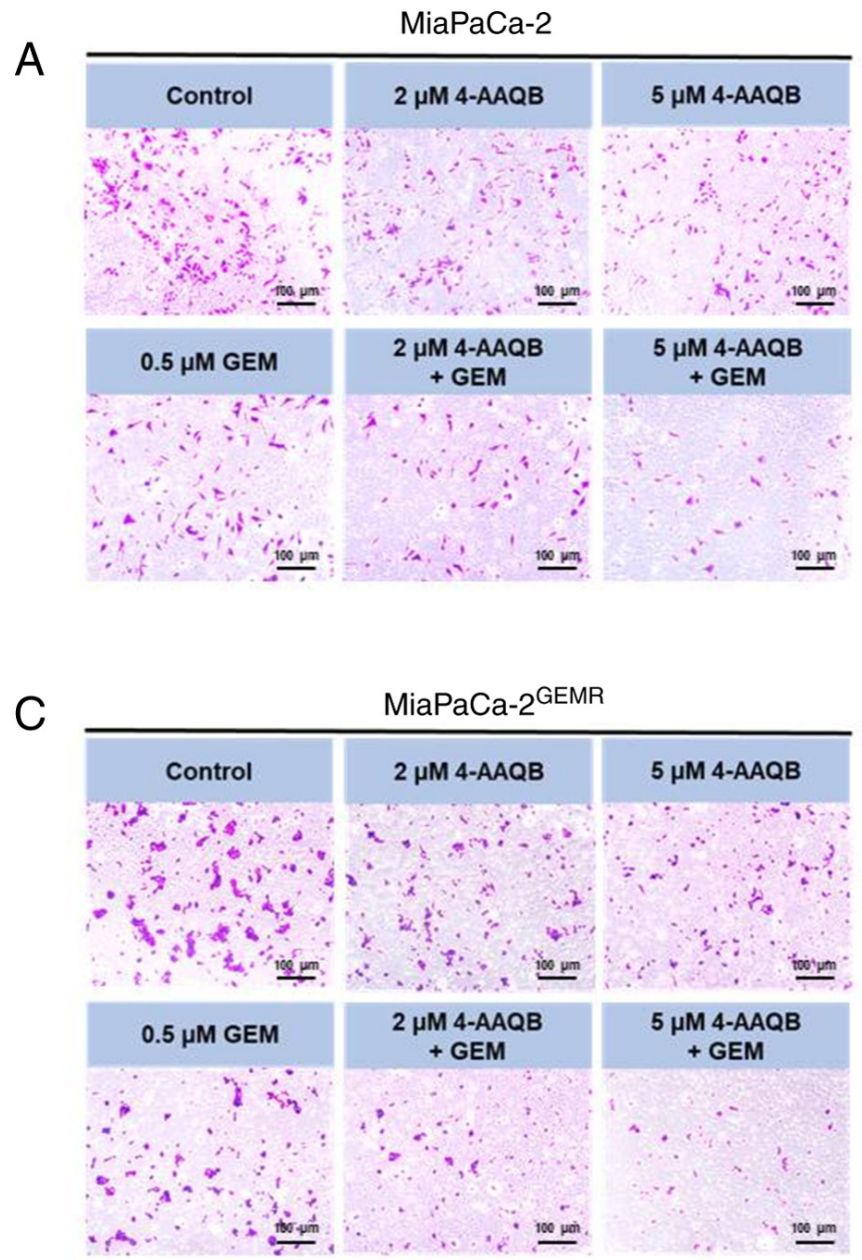
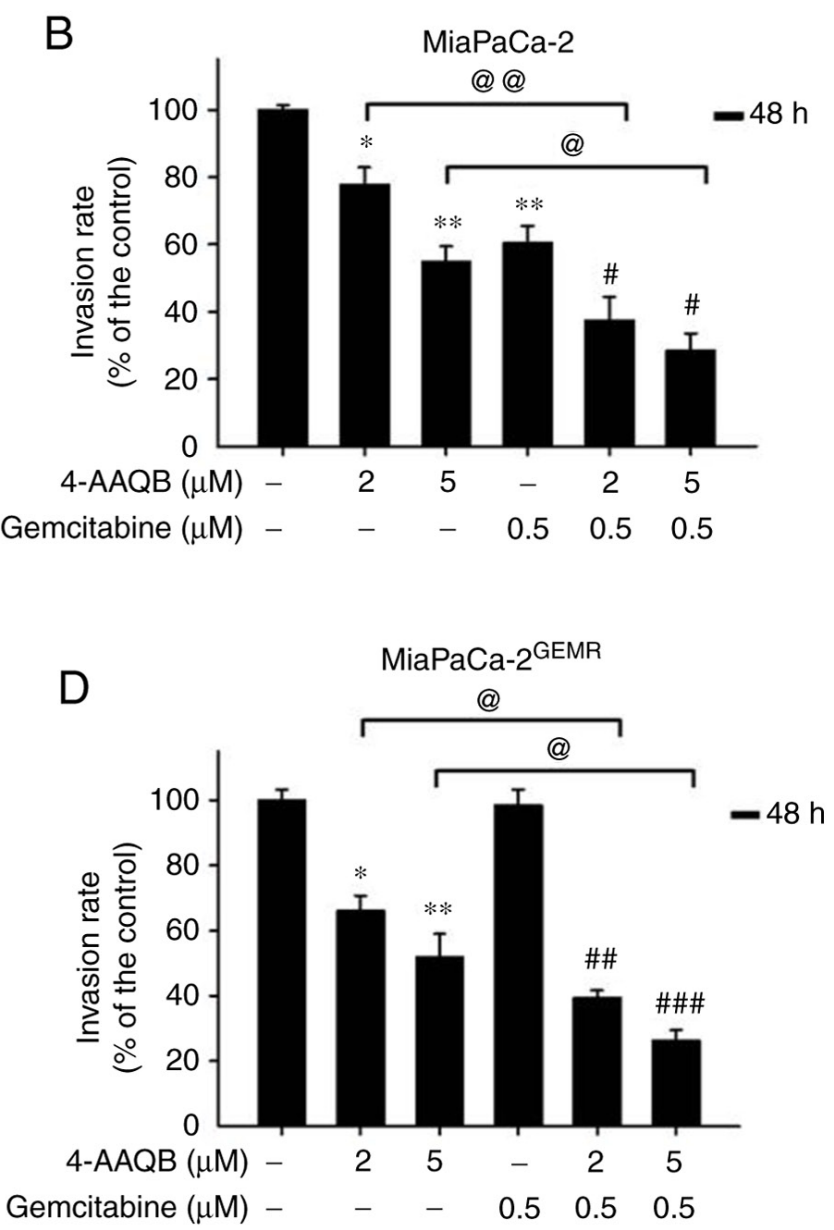

Figure 10. 4-AAQB inhibits the invasiveness of MiaPaCa-2 and MiaPaCa-2 ${ }^{\mathrm{GEMR}}$ cells. Cells were treated with 4-AAQB $(2$ and $5 \mu \mathrm{M})$ for $48 \mathrm{~h}$. (A) MiaPaCa-2 cell invasion was assessed using a Transwell assay. Representative images of the invasive cells are shown. (B) The number of invasive MiaPaCa-2 cells was calculated. (C) MiaPaCa-2 ${ }^{\text {GEMR }}$ cell invasion was assessed using a Transwell assay. Representative images of the invasive cells are shown. (D) The number of invasive MiaPaCa- $2^{\text {GEMR }}$ cells was calculated. ${ }^{*} \mathrm{P}<0.05$ and ${ }^{* *} \mathrm{P}<0.01$ vs. the untreated control cells; ${ }^{\#} \mathrm{P}<0.05,{ }^{\# \#} \mathrm{P}<0.01$, and ${ }^{\# \# \#} \mathrm{P}<0.001$ vs. the gemcitabine treated cells; ${ }^{\circledR} \mathrm{P}<0.05$ and ${ }^{\circledR} @ \mathrm{P}<0.01$ vs. the 4-AAQB treated cells. 4-AAQB, 4-Acetylantroquinonol B; GEMR, gemcitabine-resistant.

the PI3K/Akt pathway in chronic myeloid leukemia cells (45). Moreover, a previous report found that cell cycle arrest and apoptosis were induced in 4-AAQB-treated MDA-MB-231 and Hs578T human breast cancer cells (11). The findings from the present study corroborate the aforementioned results and indicate that 4-AAQB induces cell cycle arrest, apoptosis, and GEM chemosensitivity by inhibiting autophagy and the PI3K/Akt signaling axis.

Our previous studies demonstrated that the RAGE/HMGB1initiated PI3K/Akt/MDR1 biochemical cascade was strongly related to GEM chemoresistance in human pancreatic cancer cells and xenograft mouse models (18-21). Moreover, 4-AAQB has been shown to suppress autophagy and enhance cisplatin sensitivity by suppressing PI3K/Akt/mTOR/p70S6K signaling in ovarian cancer cells (46). In addition, PI3K/Akt signaling is the dominant regulator of the epithelial-mesenchymal transition (EMT), which contributes to tumor migration, invasion, and metastasis (47). 4-AAQB (5-10 $\mu \mathrm{M})$ treatment significantly downregulated VEGF and reduced cell migration and invasion in a dose-dependent manner in DLD-1, HT-29, and HCT-116 colorectal cancer cells $(48,49)$. In addition, previous evidence showed that cell migration studies had shown the importance of cell moving ability; however, a 2D substrate (Matrigel matrix) was used in the evaluation of cell invasion that may deliver inconsistent results due to cell adhesion with a different substrate such as polystyrene cell culture plate or Matrigel matrix-coated (50). A previous study compared the motility-associated protein profiles between human bladder cancer T24T cells (higher invasion but lower migration abilities) and its parental non-metastatic T24 cells (51). The results has demonstrated that high cell migratory activity does not necessarily mean high invasive activity in highly metastatic human bladder cancer T24T cells via SOD2 and MMP-2 regulated metastatic behaviors (51). Although the inhibitory effect of 4-AAQB/GEM co-treatment on invasion was greater than that on migration of MiaPaCa-2 cells, cell migration and invasion were reduced by 4-AAQB treatment in both MiaPaCa-2 and GEM-resistant cells, suggesting that 4-AAQB may play a critical role in the inhibition of tumor metastasis.

In conclusion, the present study described the mechanism through which 4-AAQB downregulates autophagy and enhances cytotoxicity, ROS accumulation, cell cycle arrest, apoptosis, and GEM sensitivity through the suppression of the RAGE/HMGB1-initiated PI3K/Akt/MDR1 signaling pathway 
in pancreatic cancer cells. Accordingly, this 4-AAQB/GEM combination strategy might represent a novel approach for the treatment of GEM-resistant pancreatic cancer.

\section{Acknowledgements}

Not applicable.

\section{Funding}

This research work was supported by a grant from Grape King Bio Ltd., Taiwan (grant no. BR-MM003).

\section{Availability of data and materials}

The datasets used and/or analyzed during the present study are available from the corresponding author on reasonable request.

\section{Authors' contributions}

YYC and GCY conceived and designed the experiments. YYC, TJL and SYC performed the experiments. YYC, TWL, SYC and CCC analyzed and interpreted the data. SYC, and GCY wrote the manuscript. YYC, SYC, and GCY confirmed the authenticity of all the raw data. All authors have read and approved the final manuscript.

\section{Ethics approval and consent to participate}

Not applicable.

\section{Patient consent for publication}

Not applicable.

\section{Competing interests}

The authors TJL, TWL, CCC are employed by Grape King Bio Ltd. All the authors declare that they have no competing interests.

\section{References}

1. Siegel RL, Miller KD, Fuchs HE and Jemal A: Cancer statistics, 2021. CA Cancer J Clin 71: 7-33, 2021.

2. Traub B, Link KH and Kornmann M: Curing pancreatic cancer. Semin Cancer Biol 76: 232-246, 2021.

3. Mizrahi JD, Surana R, Valle JW and Shroff RT: Pancreatic cancer. Lancet 395: 2008-2020, 2020.

4. Huang J, Lok V, Ngai CH, Zhang L, Yuan J, Lao XQ, Ng K, Chong $\mathrm{C}$, Zheng ZJ and Wong MCS: Worldwide burden of, risk factors for, and trends in pancreatic cancer. Gastroenterology 160: 744-754, 2021.

5. Amrutkar M and Gladhaug IP: Pancreatic cancer chemoresistance to gemcitabine. Cancers (Basel) 9: 157, 2017.

6. Binenbaum Y, Na'ara S and Gil Z: Gemcitabine resistance in pancreatic ductal adenocarcinoma. Drug Resist Updat 23: 55-68, 2015.

7. Kuang Y, Li B, Wang Z, Qiao X and Ye M: Terpenoids from the medicinal mushroom Antrodia camphorata: Chemistry and medicinal potential. Nat Prod Rep 38: 83-102, 2021.

8. Lin YW, Pan JH, Liu RH, Kuo YH, Sheen LY and Chiang BH: The 4-acetylantroquinonol $\mathrm{B}$ isolated from mycelium of Antrodia cinnamomea inhibits proliferation of hepatoma cells. J Sci Food Agric 90: 1739-1744, 2010.
9. Yen IC, Tu QW, Chang TC, Lin PH, Li YF and Lee SY: 4-Acetylantroquinonol $\mathrm{B}$ ameliorates nonalcoholic steatohepatitis by suppression of ER stress and NLRP3 inflammasome activation. Biomed Pharmacother 138: 111504, 2021.

10. Wu CH, Ou CH, Yen IC and Lee SY: 4-Acetylantroquinonol B inhibits osteoclastogenesis by inhibiting the autophagy pathway in a simulated microgravity model. Int J Mol Sci 21: 6971,2020

11. Satriyo PB, Su CM, Ong JR, Huang WC, Fong IH, Lin CC, Aryandono T, Haryana SM, Deng L, Huang CC, et al: 4-Acetylantroquinonol B induced DNA damage response signaling and apoptosis via suppressing CDK2/CDK4 expression in triple negative breast cancer cells. Toxicol Appl Pharmacol 422: 115493,2021

12. Liu HW, Su YK, Bamodu OA, Hueng DY, Lee WH, Huang CC, Deng L, Hsiao M, Chien MH, Yeh CT and Lin CM: The disruption of the $\beta$-catenin/TCF-1/STAT3 signaling axis by 4-acetylantroquinonol $\mathrm{B}$ inhibits the tumorigenesis and cancer stem-cell-like properties of glioblastoma cells, in vitro and in vivo. Cancers (Basel) 10: 491, 2018.

13. Li TY and Chiang BH: 4-Acetylantroquinonol B from Antrodia cinnamomea enhances immune function of dendritic cells against liver cancer stem cells. Biomed Pharmacother 109: 2262-2269, 2019.

14. Tang D, Loze MT, Zeh HJ and Kang R: The redox protein HMGB1 regulates cell death and survival in cancer treatment. Autophagy 6: 1181-1183, 2010.

15. Arumugam T, Ramachandran V, Gomez SB, Schmidt AM and Logsdon CD: S100P-derived RAGE antagonistic peptide reduces tumor growth and metastasis. Clin Cancer Res 18: 4356-4364, 2012.

16. Sparvero LJ, Asafu-Adjei D, Kang R, Tang D, Amin N, Im J, Rutledge R, Lin B, Amoscato AA, Zeh HJ and Lotze MT: RAGE (receptor for advanced glycation endproducts), RAGE ligands, and their role in cancer and inflammation. J Transl Med 7: 17, 2009.

17. Kang R, Tang D, Schapiro NE, Loux T, Livesey KM, Billiar TR, Wang H, Van Houten BV, Lotze MT and Zeh HJ: The HMGB1/RAGE inflammatory pathway promotes pancreatic tumor growth by regulating mitochondrial bioenergetics. Oncogene 33: 567-577, 2014.

18. Lin JH, Chen SY, Lu CC, Lin JA and Yen GC: Ursolic acid promotes apoptosis, autophagy, and chemosensitivity in gemcitabine-resistant human pancreatic cancer cells. Phytother Res 34: 2053-2066, 2020.

19. Lan CY, Chen SY, Kuo CW, Lu CC and Yen GC: Quercetin facilitates cell death and chemosensitivity through RAGE/PI3K/AKT/mTOR axis in human pancreatic cancer cells J Food Drug Anal 27: 887-896, 2019.

20. Lia ZY, Chen SY, Weng MH and Yen GC: Ursolic acid restores sensitivity to gemcitabine through the RAGE/NF- $\mathrm{B} / \mathrm{MDR} 1$ axis in pancreatic cancer cells and in a mouse xenograft model. J Food Drug Anal 29: 262-274, 2021.

21. Hsu YH, Chen SY, Wang SY, Lin JA and Yen GC: Pterostilbene enhances cytotoxicity and chemosensitivity in human pancreatic cancer cells. Biomolecules 10: 709, 2020.

22. Chang HY, Chen SY, Wu CH, Lu CC and Yen GC: Glycyrrhizin attenuates the process of epithelial-to-mesenchymal transition by modulating HMGB1 initiated novel signaling pathway in prostate cancer cells. J Agric Food Chem 67: 3323-3332, 2019.

23. Connolly P, Garcia-Carpio I and Villunger A: Cell-cycle cross talk with caspases and their substrates. Cold Spring Harb Perspect Biol 12: a036475, 2020.

24. Bedoui S, Herold MJ and Strasser A: Emerging connectivity of programmed cell death pathways and its physiological implications. Nat Rev Mol Cell Biol 21: 678-695, 2020.

25. Gil J, Ramsey D, Szmida E, Leszczynski P, Pawlowski P, Bebenek M and Sasiadek MM: The BAX gene as a candidate for negative autophagy-related genes regulator on mRNA levels in colorectal cancer. Med Oncol 34: 16, 2017.

26. Zeh HJ, Bahary N, Boone BA, Singhi AD, Miller-Ocuin JL, Normolle DP, Zureikat AH, Hogg ME, Bartlett DL, Lee KK, et al: A randomized phase II preoperative study of autophagy inhibition with high-dose hydroxychloroquine and gemcitabine/nab-paclitaxel in pancreatic cancer patients. Clin Cancer Res 26: 3126-3134, 2020.

27. Yu L, Wei J and Liu P: Attacking the PI3K/Akt/mTOR signaling pathway for targeted therapeutic treatment in human cancer. Semin Cancer Biol: S1044-579X(21)00188-7, 2021. 
28. Bernard M, Cardin GB, Cahuzac M, Ayad T, Bissada E, Guertin L, Bahig H, Nguyen-Tan PF, Filion E, Ballivy O, et al: Dual inhibition of autophagy and PI3K/AKT/mTOR pathway as a therapeutic strategy in head and neck squamous cell carcinoma. Cancers (Basel) 12: 2371, 2020.

29. Su H, Yang F, Wang Q, Shen Q, Huang J, Peng C, Zhang Y, Wan W, Wong CCL, Sun Q, et al: VPS34 acetylation controls its lipid kinase activity and the initiation of canonical and non-canonical autophagy. Mol Cell 67: 907-921.e7, 2017.

30. Jaber N, Dou Z, Chen JS, Catanzaro J, Jiang YP, Ballou LM, Selinger E, Ouyang X, Lin RZ, Zhang J and Zong WX: Class III PI3K Vps34 plays an essential role in autophagy and in heart and liver function. Proc Natl Acad Sci USA 109: 2003-2008, 2012

31. Wen C, Wang H, Wu X, He L, Zhou Q, Wang F, Chen S, Huang L, Chen J, Wang H, et al: ROS-mediated inactivation of the PI3K/AKT pathway is involved in the antigastric cancer effects of thioredoxin reductase-1 inhibitor chaetocin. Cell Death Dis 10: 809, 2019.

32. Ju HQ, Gocho T, Aguilar M, Wu M, Zhuang ZN, Fu J, Yanaga K, Huang P and Chiao PJ: Mechanisms of overcoming intrinsic resistance to gemcitabine in pancreatic ductal adenocarcinoma through the redox modulation. Mol Cancer Ther 14: 788-798, 2015.

33. Aiello NM, Brabletz T, Kang Y, Nieto MA, Weinberg RA and Stanger BZ: Upholding a role for EMT in pancreatic cancer metastasis. Nature 547: E7-E8, 2017.

34. Zheng X, Carstens JL, Kim J, Scheible M, Kaye J, Sugimoto H Wu CC, LeBleu VS and Kalluri R: Epithelial-to-mesenchymal transition is dispensable for metastasis but induces chemoresistance in pancreatic cancer. Nature 527: 525-530, 2015.

35. Parveen A, Subedi L, Kim HW, Khan Z, Zahra Z, Farooqi MQ and Kim SY: Phytochemicals targeting VEGF and VEGF-related multifactors as anticancer therapy. J Clin Med 8: 350, 2019.

36. Hosein AN, Brekken RA and Maitra A: Pancreatic cancer stroma: An update on therapeutic targeting strategies. Nat Rev Gastroenterol Hepatol 17: 487-505, 2020.

37. Zhao H, Wu S, Li H, Duan Q, Zhang Z, Shen Q, Wang C and Yin T: ROS/KRAS/AMPK signaling contributes to gemcitabine-induced stem-like cell properties in pancreatic cancer. Mol Ther Oncolytics 14: 299-312, 2019.

38. Hu W, Liu Q, Pan J and Sui Z: miR-373-3p enhances the chemosensitivity of gemcitabine through cell cycle pathway by targeting CCND2 in pancreatic carcinoma cells. Biomed Pharmacother 105: 887-898, 2018

39. Lin YW and Chiang BH: 4-acetylantroquinonol B isolated from Antrodia cinnamomea arrests proliferation of human hepatocellular carcinoma HepG2 cell by affecting p53, p21 and p27 levels. J Agric Food Chem 59: 8625-8631, 2011.

40. Kang R, Tang D, Lotze MT and Zeh HJ III: RAGE regulates autophagy and apoptosis following oxidative injury. Autophagy 7 : 442-444, 2011
41. Kang R, Tang D, Livesey KM, Schapiro NE, Lotze MT and Zeh HJ III: The receptor for advanced glycation end-products (RAGE) protects pancreatic tumor cells against oxidative injury. Antioxid Redox Signal 15: 2175-2184, 2011.

42. Liu M, Bamodu OA, Huang WC, Zucha MA, Lin YK, Wu ATH, Huang CC, Lee WH, Yuan CC, Hsiao M, et al: 4-Acetylantroquinonol B suppresses autophagic flux and improves cisplatin sensitivity in highly aggressive epithelial cancer through the PI3K/Akt/mTOR/p70S6K signaling pathway. Toxicol Appl Pharmacol 325: 48-60, 2017.

43. Piffoux M, Eriau E and Cassier PA: Autophagy as a therapeutic target in pancreatic cancer. Br J Cancer 124: 333-344, 2021.

44. Liu PF, Tsai KL, Hsu CJ, Tsai WL, Cheng JS, Chang HW, Shiau CW, Goan YG, Tseng $\mathrm{HH}$, Wu CH, et al: Drug repurposing screening identifies tioconazole as an ATG4 inhibitor that suppresses autophagy and sensitizes cancer cells to chemotherapy. Theranostics 8: 830-845, 2018.

45. Shao S, Li S, Qin Y, Wang X, Yang Y, Bai H, Zhou L, Zhao C and Wang C: Spautin-1, a novel autophagy inhibitor, enhances imatinib-induced apoptosis in chronic myeloid leukemia. Int J Oncol 44: 1661-1668, 2014

46. Tam C, Rao S, Waye MMY, Ng TB and Wang CC: Autophagy signals orchestrate chemoresistance of gynecological cancers. Biochim Biophys Acta Rev Cancer 1875: 188525, 2021.

47. Larue L and Bellacosa A: Epithelial-mesenchymal transition in development and cancer: Role of phosphatidylinositol 3 kinase/AKT pathways. Oncogene 24: 7443-7454, 2005.

48. Chang TC, Yeh CT, Adebayo BO, Lin YC, Deng L, Rao YK, HuangCC,Lee WH,Wu AT,HsiaoM, etal: 4-Acetylantroquinonol B inhibits colorectal cancer tumorigenesis and suppresses cancer stem-like phenotype. Toxicol Appl Pharmacol 288: 258-268, 2015.

49. Bamodu OA, Yang CK, Cheng WH, Tzeng DTW, Kuo KT, Huang CC, Deng L, Hsiao M, Lee WH and Yeh CT: 4-Acetyl-antroquinonol B suppresses SOD2-enhanced cancer stem cell-like phenotypes and chemoresistance of colorectal cancer cells by inducing hsa-miR-324 re-expression. Cancers (Basel) 10: 269, 2018.

50. Friedl $\mathrm{P}$ and Wolf $\mathrm{K}$ : Tumour-cell invasion and migration: Diversity and escape mechanisms. Nat Rev Cancer 3: 362-374, 2003.

51. Jin H, Yu Y, Hu Y, Lu C, Li J, Gu J, Zhang L, Huang H, Zhang D, Wu XR, et al: Divergent behaviors and underlying mechanisms of cell migration and invasion in non-metastatic T24 and its metastatic derivative T24T bladder cancer cell lines. Oncotarget 6 : 522-536, 2015 .

This work is licensed under a Creative Commons Attribution-NonCommercial-NoDerivatives 4.0 International (CC BY-NC-ND 4.0) License. 